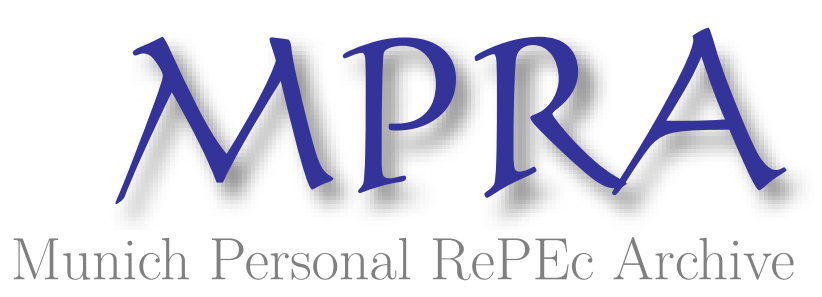

\title{
The Signalling Channel of Negative Interest Rates
}

de Groot, Oliver and Haas, Alexander

1 August 2019

Online at https://mpra.ub.uni-muenchen.de/95479/

MPRA Paper No. 95479, posted 13 Aug 2019 02:19 UTC 


\title{
The Signalling Channel of Negative Interest Rates*
}

\author{
Oliver de Groot ${ }^{\dagger} \quad$ Alexander Haas ${ }^{\ddagger}$
}

Current version: August 1, 2019

First version: February 15, 2018

\begin{abstract}
Negative interest rates are a new (and controversial) monetary policy tool. This paper studies a novel signalling channel and asks whether negative rates can be 1) an effective and 2) an optimal policy tool. 1) We build a financial-friction newKeynesian model in which monetary policy can set a negative reserve rate, but deposit rates are constrained by zero. All else equal, a negative rate contracts bank net worth and increases credit spreads (the costly "interest margin" channel). However, it also signals lower future deposit rates, even with current deposit rates constrained, boosting aggregate demand and net worth. Quantitatively, we find the signalling channel dominates, but the effectiveness of negative rates depends crucially on three factors: i) degree of policy inertia, ii) level of reserves, iii) zero lower bound duration. 2) In a simplified model we prove two necessary conditions for the optimality of negative rates: i) time-consistent policy setting, ii) preference for policy smoothing.
\end{abstract}

Keywords: Monetary policy, Taylor rule, Forward guidance, Liquidity trap JEL Classifications: E44, E52, E61

*We thank Radu Cristea for excellent research assistance. We thank Carlo Altavilla, Paolo Bonomolo, Flora Budianto, Giacomo Carboni, Vania Esady, Andrea Ferrero, Marcel Fratzscher, Marc Giannoni, Mario Giarda, Jochen Güntner, Wouter den Haan, Martín Harding, Peter Karadi, Matthijs Katz, Nobuhiro Kiyotaki, Tobias König, Jenny Körner, Bettina Landau, Wolfgang Lemke, Karel Mertens, Anton Nakov, Kalin Nikolov, Alex Richter, Tano Santos, Sebastian Schmidt, Stephanie Schmitt-Grohé, Yves Schüler, João Sousa, Mathias Trabandt, Giovanni Violante, and participants at many central bank and university seminars, workshops and conferences for comments and discussions that improved the paper. Disclaimer: Part of this paper was written while both authors were employed at the European Central Bank. The views in this paper are those of the authors and do not necessarily reflect the views of the European Central Bank, the Governing Council or its staff.

${ }^{\dagger}$ University of Liverpool Management School, Liverpool, L69 7ZH, UK (oliverdegroot@gmail.com)

${ }^{\ddagger}$ University of Oxford \& DIW Berlin, Manor Rd, OX1 3UQ, UK (alexander.haas@economics.ox.ac.uk) 


\section{Introduction}

In the aftermath of the Great Recession, negative interest rates have become an additional policy tool for several central banks around the world while others have kept interest rates in positive territory, despite need for additional monetary accommodation. In the euro area, both the European Central Bank's (ECB) deposit facility rate - the rate the ECB pays on bank reserves held at the ECB - and the overnight interbank market rate (EONIA) have been negative since June 2014 (Figure 1(a)). At the time of writing, the deposit facility rate stands at $-0.4 \%{ }^{1}$ At the same time household deposit rates have declined but remain positive. Figure 1(b) plots the histogram of household deposit rates across individual banks in the euro area in June 2014 and December 2017. Across this period, a growing fraction of deposits has earned a zero interest rate, but virtually no banks have passed on the negative reserve rate to household depositors. Moreover, banks earning a negative interest rate on reserves did not prevent the accumulation of excess reserves, with total reserves rising to over $20 \%$ of deposits in 2017 (Figure 1(c)). ${ }^{2}$

This raises four important questions. One, given that banks do not (or cannot) pass on negative interests rates to households, what is the transmission channel through which they operate? Two, given that a large fraction of the banking systems' assets are reserves that earn a negative interest rate, what are the consequences for the health of the banking system and its ability to create credit? Three, when the various effects of negative interest rates are taken into account, is it an effective policy tool for supporting output and inflation? Four, under what conditions should negative rates be in the toolkit of an optimal policymaker? This paper studies a novel signalling channel to address these questions and asks whether negative rates can be an effective and optimal policy tool.

The first contribution of this paper explores a novel signalling channel through which negative interest rates on reserves can be expansionary, even when deposit rates have a zero lower bound (ZLB). We build a new-Keynesian model with financial frictions (in the spirit of Gertler and Karadi, 2011) in which banks hold reserves at the central bank and monetary policy can set a negative reserve rate, but - in line with the empirical evidence- deposit rates are constrained by zero.

\footnotetext{
1 The ECB is not unique in having adopted a negative interest rate policy. In Switzerland, the SNB set its target rate for the 3-month LIBOR CHF at $-0.75 \%$ to $0.25 \%$ in December 2014 , and lowered it to $-1.25 \%$ to $-0.25 \%$ in January 2015. In Sweden, the Riksbank set its deposit rate to $-0.5 \%$ in July 2014. In February 2015, it set its deposit and repo rate to $-0.85 \%$ and $-0.1 \%$, respectively, and in February 2016 both rates reached their lowest point of $-1.25 \%$ and $-0.5 \%$. In Denmark, the Danmarks Nationalbank set its certificates of deposit rate at $-0.05 \%$ in September 2014, reaching its lowest point of $-0.75 \%$ in February 2015. In Japan, the BOJ set the short-term policy interest rate at $-0.1 \%$ in January 2016.

2 The overall rise in reserves has been the result of the ECB's liquidity and asset purchase programmes. However, deposit creation and lending decisions of the banking system determine the amount of reserves as a ratio of deposits and the split of reserves between required and excess.
} 
Figure 1: Interest rates and reserves in the euro area

(a) Interest rates

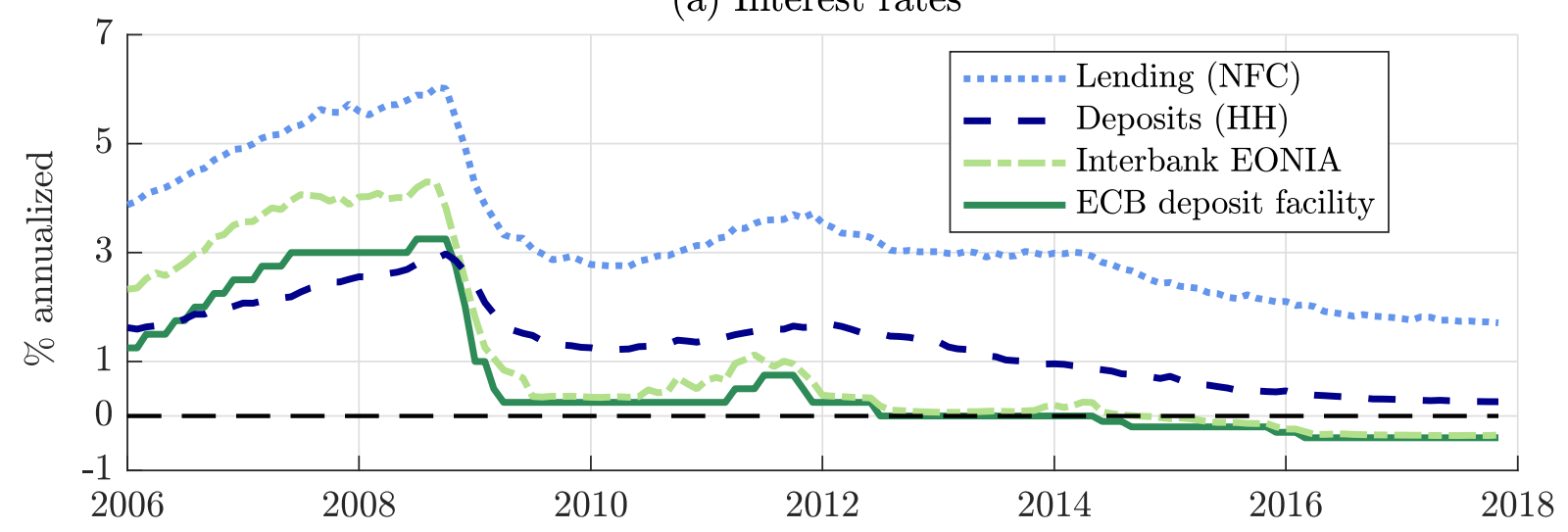

(b) Deposit rates $(\%)$

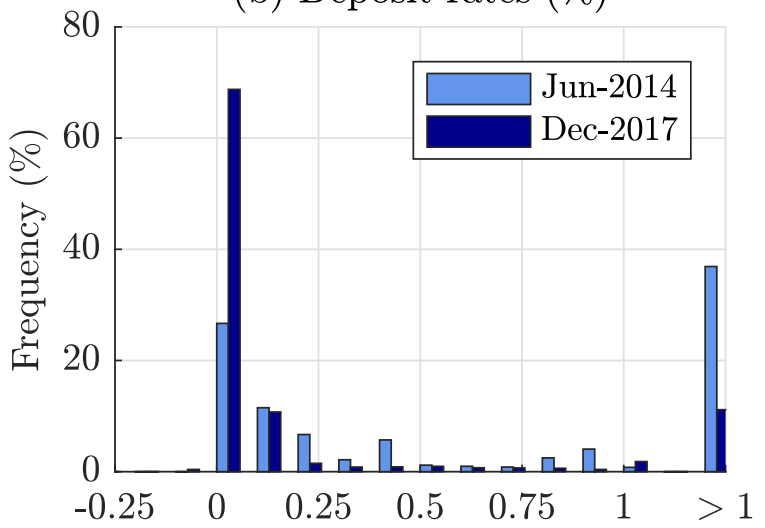

(c) Reserves

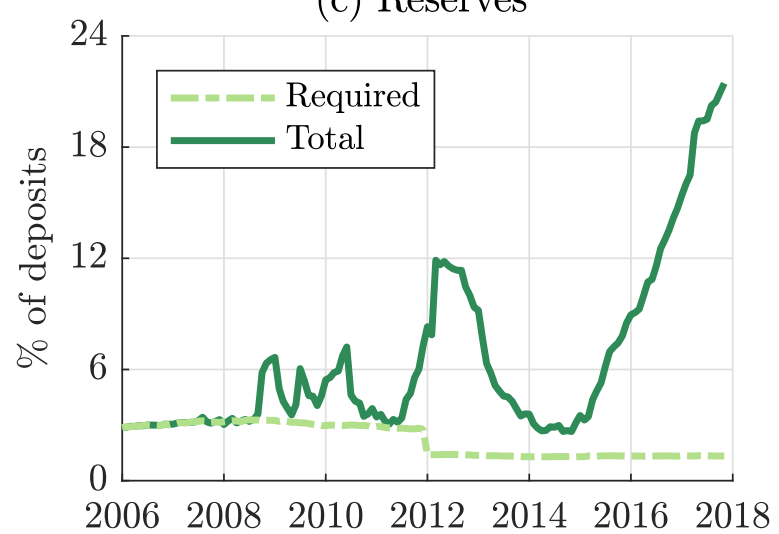

Note: In (a) NFC and HH denote non-financial corporation and household composites, respectively; EONIA is the euro area overnight interbank market rate. In (b) deposit rates are on outstanding amounts as reported by individual banks, plotted as a fraction of total deposits in each bucket. In (c) deposits are $\mathrm{HH}$ and NFC deposits; excess reserves are given by total reserves minus required reserves. Source: ECB.

In the model, when the economy is away from the ZLB, an arbitrage condition ensures that the interest rate on reserves and the interest rate on deposits move in tandem, and the behavior of the model is observationally equivalent to a model without reserves. However, when the central bank introduces a negative reserve rate, the deposit rate (the rate that enters the households' Euler equation) is bounded by zero, creating a wedge between the return on reserve assets and the ultimate funding source of banks - deposits. Thus, all else equal, a negative reserve rate acts like a contractionary bank net worth shock (henceforth, the costly "interest margin" channel of negative interest rates), where the size of the shock is scaled by the amount of reserves in the system. As a result of the financial friction, this fall in net worth widens credit spreads (raising lending rates vis-a-vis deposit rates) and depresses investment demand. This direct, or intratemporal, effect of negative interest rates has been a key criticism of banks to negative rate policies in Europe and elsewhere. ${ }^{3}$

\footnotetext{
${ }^{3}$ See, for example, Financial Times, August 30, 2017:

"Poll exposes tensions between ECB and Germany's small banks".
} 
This paper shows that, in addition to this channel, there are also substantial positive general equilibrium consequences of negative interest rates that are less directly ascribable to the policy. In particular, we emphasize the positive role negative rates can play in terms of signalling future policy (henceforth, the "signalling" channel of negative interest rates). ${ }^{4}$ An inertial Taylor-type rule ensures that the cut into negative territory can signal that deposit rates will remain lower-for-longer even though current deposit rates do not change, generating an expansionary intertemporal aggregate demand effect.

We show that, for a carefully calibrated quantitative model, the contractionary intratemporal effect of negative interest rates via the interest margin channel is more than offset by the expansionary intertemporal aggregate demand effect via the signalling channel. Moreover, the intertemporal demand effect raises asset values, banks experience capital gains, reversing the fall in net worth, compressing credit spreads (i.e. lowering lending rates) and boosting investment demand. However, the effectiveness of monetary policy in negative territory relative to standard monetary policy depends crucially on three factors: i) a higher degree of policy inertia strengthens the expansionary signalling channel, ii) a greater level of reserves in the banking system magnifies the contractionary interest margin channel, iii) a longer expected zero lower bound duration both depresses the expansionary signalling channel and magnifies the contractionary interest rate channel.

The second contribution of this paper is to study optimal policy and prove conditions under which an optimal policymaker would include negative interest rates as part of its policy toolkit. Using a stylized version of the above model, we prove that an optimal policymaker uses negative interest rates if and only if the following two conditions simultaneously hold: i) it sets time-consistent discretionary policy (i.e. it cannot commit to future promises), and ii) it has an intrinsic preference for policy smoothing. Under these conditions, lowering the interest rate on reserves into negative territory can act as a tangible signal of maintaining lower rates in the future. In contrast, a policymaker that can fully commit to future promises would not use negative interest rates. It can generate a credible future path of deposit rates without incurring the costly effect of a negative reserve rate via the interest margin channel. Equally, a discretionary policymaker without a preference for smoothing has no ability to signal and thus negative interest rates generate a direct cost to banks without any benefits. ${ }^{5}$

\footnotetext{
4 Note that our use of the term "signalling" is different from the literature on imperfect information and the dispersion of information through central bank decisions such as in, for example, Melosi (2017). Instead, our usage of the term signalling captures a central bank's ability to give tangible signals about future policy, akin to Bhattarai et al. (2015)'s signalling theory of quantitative easing.

${ }^{5}$ Our signalling channel is akin to forward guidance, except forward guidance is an "open mouth" operation while negative interest rates provide tangible guidance about the future precisely because policy smoothing is a well documented characteristic of monetary policy.
} 
Literature There is a growing empirical literature assessing the transmission and impact of negative interest rates. Both Jobst and Lin (2016) and Eisenschmidt and Smets (2018) provide overviews on the use of negative interest rates across countries. For the euro area, Eisenschmidt and Smets (2018) document the empirical regularity - consistent with our model - that banks have not lowered household deposits rates below zero. However, they do observe that there is a higher (yet still small) prevalence of negative rates charged on firm deposits. They conclude that negative rates have been broadly successful in easing financial conditions and creating modest credit growth, despite some adverse effects on bank balance sheets. Altavilla et al. (2018) analyze euro area bank balance sheet data and estimate the impact of a range of unconventional monetary policy measures, including negative rates, on bank profitability. In line, with our paper, they identify a direct interest margin channel but find that negative rates also caused a substantial rise in banks' asset and equity value. Demiralp et al. (2019) find evidence for significant bank portfolio rebalancing in response to negative interest rates. Heider et al. (2019) show that banks adjust both lending quantity and risk profile in response to negative rates. ${ }^{6}$

The theoretical literature on negative rates is more limited. ${ }^{7}$ Eggertsson et al. (2019) is most closely related to our paper. They build a new-Keynesian model but, in contrast to this paper, find that negative rates are, at best, ineffective, and at worst contractionary for output. This results from an intermediation cost term that becomes activated at negative rates. Compared to this approach, we take three further steps, by microfounding the financial friction, studying the role of policy inertia, and characterizing optimal policy. Brunnermeier and Koby (2018) build a partial equilibrium model and show that reducing the policy rate can be contractionary, even at positive interest rates. They define a (potentially time-varying) "reversal rate" as a notional rate below which a central bank should not go. This reversal rate results from banks coming up against a binding leverage constraint. Rognlie (2016) studies optimal policy in a model without banks where a negative rate can raise aggregate demand but also inefficiently subsidizes paper currency. In his model, negative rates have a positive intratemporal aggregate demand effect, whereas in our model, the intratemporal aggregate demand effect is absent because deposit rates are constrained by the ZLB. Porcellacchia (2019) also considers optimal policy and focuses on the same central bank policy instrument we do - interest on reserves - but introduces a ZLB constraint on the interbank market rate. He highlights a maturity-transformation channel of negative rates: Negative rates boost aggregate demand but hurt bank intermediation and thereby liquidity-risk insurance.

\footnotetext{
${ }^{6}$ In addition, Wu and Xia (2018) and Lemke and Vladu (2017) build term structure models to account for the effect of negative rates on the yield curve.

${ }^{7}$ It has been brought to our attention that our signalling channel connects to the finance literature on the theory of costly signalling. In Bhattacharya (1979), for example, firms pay out dividends, despite it being costly, to signal to investors strong future cash flows.
} 
Our paper also connects with two other literatures, one on signalling and another on policy smoothing. In terms of signalling, our paper is close in spirit to Bhattarai et al. (2015), who present a signalling theory of quantitative easing. In their model, quantitative easing is effective because the government commits to honour outstanding debt obligations, enabling the discretionary policymaker to generate a credible signal of low future interest rates. Technically, the discretionary policymaker needs a state variable to signal; in our model, the state variable is the lagged reserve rate, in their model it is the debt stock. In terms of policy smoothing, our paper is closely related to Nakata and Schmidt (2019), who show that delegating policy to a policymaker with a preference for smoothing increases welfare in an economy subject to occasional ZLB episodes. Our results take this one step further. We show that delegating to a policymaker with a smoothing preference opens up the possibility of an additional (welfare improving) policy instrument-negative rates.

The remainder of the paper proceeds as follows: Section 2 describes the main model and our baseline parameterization. Section 3 presents results on the effectiveness of negative interest rates. Section 4 describes a simplified model and establishes conditions under which a negative interest rate policy is optimal. Section 5 concludes.

\section{The model}

The basis of this model is a financial-friction new-Keynesian model of the type developed by Gertler and Karadi (2011). To this we add reserves, a liability of the central bank and an asset on financial intermediaries' (henceforth, banks') balance sheets. We assume that banks demand to hold a fraction of their deposits as reserves. The interest paid on reserves by the central bank is the instrument of monetary policy. Household (nominal) deposit rates feature a ZLB. Away from the ZLB, arbitrage ensures the interest rate on reserves and the interest rate on household deposits is equalized. In this case, equilibrium outcomes are independent of reserves and the model behaves like a standard new-Keynesian model. However, the central bank - described by an inertial policy rule - can also set a negative (nominal) interest rate on reserves, creating a wedge in the aforementioned arbitrage condition. The financial friction constrains banks' ability to intermediate funds between households and firms, with the credit spread (between the return on deposits and the expected return on capital) largely determined by banks' net worth. Typically, a financial friction amplifies the effect of monetary policy. In this environment, it is not clear, ex ante, whether it will amplify or depress the effectiveness of a negative interest rate policy.

The remainder of the section describes the decision problem of households, three types of non-financial producers, financial intermediaries, and the central bank in the model. 


\subsection{Households}

A representative household is composed of a fraction $f$ workers and $1-f$ bankers, with perfect consumption insurance. Workers and bankers switch with probability $1-\theta$ and when they do, bankers transfer retained profits back to the household. The household likes (habit-adjusted) consumption, $\tilde{c}_{t} \equiv c_{t}-\hbar c_{t-1}$, dislikes labor, $l_{t}$, and discounts the future with $\beta_{t}$, which is exogenous and stochastic. Savings are either kept in cash, $v_{t}$, that pays a zero nominal return, or in deposits, $d_{t}$. Deposits are held at banks and earn the nominal return $r_{d, t}$. The household makes contingent plans for consumption, labor supply and savings to maximize lifetime utility. The household solves

$$
\nu_{h, t}=\max _{\left\{c_{t}, d_{t}, v_{t}, l_{t}\right\}}\left(\frac{\tilde{c}_{t}^{1-\sigma}}{1-\sigma}-\frac{\chi}{1+\varphi} l_{t}^{1+\varphi}\right)+\beta_{t} \mathbb{E}_{t} \nu_{h, t+1}
$$

subject to

$$
p_{t} c_{t}=p_{t} w_{t} l_{t}+r_{d, t-1} d_{t-1}-d_{t}+v_{t-1}-v_{t}+\Omega_{t},
$$

where $p_{t}$ is the price of consumption, $w_{t}$ is the real wage, and $\Omega_{t}$ is the sum of firm and bank profits and lump-sum transfers. The household's first-order conditions are given by

$$
\begin{aligned}
1 & =\mathbb{E}_{t} m_{t, t+1} r_{d, t} / \pi_{t+1}, \\
\mu_{t} w_{t} & =\chi l_{t}^{\varphi},
\end{aligned}
$$

where $m_{t, t+1} \equiv \beta_{t} \mu_{t+1} / \mu_{t}$ is the household's stochastic discount factor, the marginal utility of consumption is given by $\mu_{t} \equiv \tilde{c}_{t}^{-\sigma}-\beta_{t} \hbar \mathbb{E}_{t} \tilde{c}_{t+1}^{-\sigma}$, and $\pi_{t} \equiv p_{t} / p_{t-1}$ is the gross inflation rate. Since the household will not hold deposits with a nominal return less than zero, the following inequality must also apply: $r_{d, t} \geq 1$.

\subsection{Financial intermediaries}

A banker $i$ uses net worth, $n_{i, t}$, and household deposits, $d_{i, t}$, to buy $s_{i, t}$ units of firm equity at price $q_{t}$, and $a_{i, t}$ units of central bank reserves. Firm equity pays a stochastic real return, $r_{k, t+1}$, next period while central bank reserves pay a predetermined nominal interest rate, $r_{t}$. Within a period, the timing is as follows: One, bankers collect asset returns and pay creditors. Two, bankers exit with probability $1-\theta$. An exiting banker is replaced by a worker with an initial endowment of net worth equal to a fraction $\omega$ of total firm equity in the previous period. Three, bankers issue new deposits and buy new assets. We assume that bankers hold at least a fraction $\alpha$ of deposits as central 
bank reserves. This is a reduced form mechanism for capturing banks' preference for self-insuring against idiosyncratic liquidity risk. ${ }^{8}$ Four, at this stage a banker can divert a fraction $\lambda$ of its private sector assets. In this case, the banker's creditors can force bankruptcy and recover the remaining fraction of assets. This assumption introduces an agency problem that creates a financial friction and makes bankers' net worth a crucial determinant of equilibrium outcomes in the model. ${ }^{9}$ Bankers solve

$$
\nu_{f, t}=\max _{\left\{s_{i, t}, a_{i, t}, d_{i, t}, n_{i, t}\right\}} \mathbb{E}_{t} m_{t, t+1}\left((1-\theta) n_{i, t+1}+\theta \nu_{f, t+1}\right)
$$

subject to

$$
\begin{aligned}
q_{t} s_{i, t}+a_{i, t} & =d_{i, t}+n_{i, t}, \\
\nu_{f, t} & \geq \lambda q_{t} s_{i, t}, \\
a_{i, t} & \geq \alpha d_{i, t}, \\
n_{i, t+1} & =r_{k, t+1} q_{t} s_{i, t}+\frac{r_{t}}{\pi_{t+1}} a_{i, t}-\frac{r_{d, t}}{\pi_{t+1}} d_{i, t},
\end{aligned}
$$

where the constraints are the balance sheet constraint, incentive compatibility constraint, reserve constraint and net worth accumulation equation, respectively. We calibrate the model such that the incentive constraint is always binding.

The central bank supplies reserves elastically and sets the interest rate on reserves. Since banks are competitive, arbitrage ensures that $a_{i, t}=\alpha d_{i, t}$ and $r_{t}=r_{d, t}$ as long as $r_{d, t} \geq 0$.

In equilibrium, $s_{t}=k_{t}$, where $k_{t}$ is the aggregate capital stock in the economy, and bankers will have a common leverage ratio, denoted $\phi_{t} \equiv q_{t} k_{t} / n_{t}=q_{t} k_{i, t} / n_{i, t}$. As outlined in Appendix A.1, it is possible to express the financial intermediaries' problem in just two equations, with the binding incentive compatibility constraint and the evolution of aggregate net worth given by

$$
\begin{aligned}
\lambda \phi_{t} & =\mathbb{E}_{t} m_{t, t+1}\left((1-\theta)+\theta \lambda \phi_{t+1}\right)\left(r_{k, t+1} \phi_{t}-\frac{r_{d, t}-\alpha r_{t}}{(1-\alpha) \pi_{t+1}}\left(\phi_{t}-1\right)\right), \\
n_{t} & =\theta\left(r_{k, t} \phi_{t-1}-\frac{r_{d, t-1}-\alpha r_{t-1}}{(1-\alpha) \pi_{t}}\left(\phi_{t-1}-1\right)\right) n_{t-1}+\omega q_{t} k_{t-1} .
\end{aligned}
$$

When $r_{t}=r_{d, t}$, reserves are neutral and have no effect on equilibrium outcomes since $\alpha$ drops out of both equations. However, when $r_{t}<0$, banks cannot pass this on in terms of lower deposit rates and the presence of reserves has real consequences.

\footnotetext{
8 For a more rigorously microfounded model of idiosyncratic liquidity risk, see Güntner (2015) or Bianchi and Bigio (2018).

${ }^{9}$ We assume this agency problem does not apply to central bank reserves.
} 


\section{$2.3 \quad$ Producers}

\subsubsection{Capital goods firms}

A representative capital goods firm repairs depreciated capital and produces new capital. Existing capital depreciates at rate $\delta$ and is refurbished at unit cost. New capital goods, $k_{n, t}$, are produced using technology $k_{n, t}=f\left(i_{n, t}, i_{n, t-1}\right)$, where $i_{n, t}$ is investment in new capital formation. The capital goods firm solves

$$
\nu_{c, t}=\max _{i_{n, t}}\left(q_{t} k_{n, t}-i_{n, t}\right)+\mathbb{E}_{t} m_{t, t+1} \nu_{c, t+1}
$$

The first-order condition is given by $1=q_{t} f_{1, t}+\mathbb{E}_{t} m_{t, t+1} q_{t+1} f_{2, t+1}$, where $f_{j, t}$ is the derivative of $f(\cdot)$ with respect to argument $j$. With quadratic flow adjustment cost, $f(\cdot) \equiv\left(1-\left(\eta_{i} / 2\right)\left(\left(i_{n, t}+i_{s s}\right) /\left(i_{n, t-1}+i_{s s}\right)-1\right)^{2}\right) i_{n, t}$, where $i_{s s}=\delta k_{s s}$ is steady state investment pertaining to gross investment $i_{t}=f\left(i_{n, t}, i_{n, t-1}\right)+\delta k_{t-1}$.

The exact functional form of the optimal investment decision is given in Appendix A.2. Capital accumulation follows $k_{t}=k_{t-1}+f\left(i_{n, t}, i_{n, t-1}\right)$.

\subsubsection{Intermediate goods firms}

A representative intermediate goods firm produces goods, $y_{t}$, using technology $k_{t-1}^{\gamma} l_{t}^{1-\gamma}$. Labor is rented in a competitive market, and the demand for labor is given by $w_{t}=$ $p_{m, t}(1-\gamma) y_{t} / l_{t}$, where $p_{m, t}$ is the real intermediate output price. Profits per unit of capital are given by $p_{m, t} \gamma y_{t} / k_{t-1}$. Firms need external finance to purchase capital goods. At the beginning of the period, they issue $s_{t}$ units of equity to bankers at price $q_{t}$. In return, the banker receives the realized return on a unit of capital next period, given by

$$
r_{k, t}=\frac{p_{m, t} \gamma y_{t} / k_{t-1}+q_{t}-\delta}{q_{t-1}}
$$

\subsubsection{Retail firms}

Retail firms repackage intermediate output one-for-one. Final output, $y_{t}$, is a CES aggregate of differentiated retail firms' output given by $y_{t}=\left(\int_{0}^{1} y_{i, t}^{(\epsilon-1) / \epsilon} d i\right)^{\epsilon /(\epsilon-1)}$, where $y_{i, t}$ is output by retailer $i$ and $\epsilon$ is the elasticity of substitution between goods. Cost minimization ensures that $y_{i, t}=\left(p_{i, t} / p_{t}\right)^{-\epsilon} y_{t}$ and $p_{t}=\left(\int_{0}^{1} p_{i, t}^{1-\epsilon} d i\right)^{1 /(1-\epsilon)}$. Retail firms face nominal price rigidities of the type presented in Calvo (1983). Each period, a firm is able to adjust its price with probability $1-\iota$. If no adjustment is possible, the price can 
be indexed to the lagged rate of inflation. The retail firm objective is given by

$$
\max _{p_{i, t}} \mathbb{E}_{t} \sum_{\tau=0}^{\infty} \iota^{\tau} m_{t, t+\tau}\left(\frac{p_{i, t}}{p_{t+\tau}} \prod_{k=1}^{\tau} \pi_{t+k-1}^{\gamma_{p}}-p_{m, t+\tau}\right) y_{i, t+\tau}
$$

where $\gamma_{p}$ is the degree of price indexation and $p_{m, t}$ constitutes retail firms' marginal cost. The first-order condition is given by

$$
\mathbb{E}_{t} \sum_{\tau=0}^{\infty} \iota^{\tau} m_{t, t+\tau}\left(\frac{p_{*, t}}{p_{t+\tau}} \prod_{k=1}^{\tau} \pi_{t+k-1}^{\gamma_{p}}-\frac{\epsilon}{\epsilon-1} p_{m, t+\tau}\right) y_{i, t+\tau}=0
$$

where $p_{*, t}$ is the optimal reset price. The aggregate price index can be written as

$$
p_{t}=\left((1-\iota) p_{*, t}^{1-\epsilon}+\iota p_{t-1}^{1-\epsilon}\right)^{1 /(1-\epsilon)} .
$$

\subsection{Monetary policy}

The central bank's policy instrument is the nominal interest rate on reserves, which when unconstrained follows a Taylor-type inertial policy rule given by

$$
r_{T, t}=\left(r_{s s}\left(\frac{\pi_{t}}{\pi_{s s}}\right)^{\phi_{\pi}}\left(\frac{x_{t}}{x_{s s}}\right)^{\phi_{x}}\right)^{1-\rho} r_{t-1}^{\rho} \exp \left(\varepsilon_{m, t}\right)
$$

where $r_{T, t}$ is the rate implied by the policy rule, $x_{t}$ is marginal cost and proxies the output gap, and $\varepsilon_{m, t}$ is a monetary policy shock. We assume zero steady-state inflation, $\pi_{s s}=1 .^{10}$ $\rho$ describes the degree of inertia in the policy rule. Notice that the inertial term is the lagged interest rate on reserves. Thus, the policy rule implied rate exhibits no inertia when the rate on reserves is bounded at zero. ${ }^{11}$ We compare three scenarios:

I. The unconstrained scenario (UNC) in which

$$
r_{t}=r_{d, t}=r_{T, t}
$$

In this scenario, both the nominal reserve and deposit rate are unconstrained by the ZLB and can turn negative.

\footnotetext{
${ }^{10}$ Coibion et al. (2012) derive a utility-based welfare function allowing for positive steady-state inflation and find that given infrequent but costly ZLB periods, the optimal inflation rate is positive but small.

11 Other studies have considered policy rules in which the inertial term is on the Taylor-rule implied rate, $r_{T, t}$, rather than the actual policy rate, $r_{t}$. To the extent this rule is credible $\left(r_{T, t}\right.$ is a latent variable), such a policy rule also increases the effectiveness of monetary policy in a standard ZLB scenario. Thus, this latter formulation is more akin to explicit forward guidance, whereas in our specification inertia is a structural feature of monetary policy that is orthogonal to whether the economy is at the ZLB or not.
} 
II. The deposit rate-only ZLB scenario (ZLB: $r_{d}$ only) in which

$$
r_{t}=r_{T, t} \quad \text { and } \quad r_{d, t}=\max \left\{1, r_{T, t}\right\}
$$

In this scenario - our baseline to study the effects of negative interest rates - the deposit rate is bounded by zero, but the interest rate paid on reserves can fall below zero. While the central bank can decrease the policy rate into negative territory, there is no contemporaneous effect on nominal deposit rates as these are bounded below.

III. The standard ZLB scenario (ZLB: $r_{d} \& r$ ) in which

$$
r_{t}=r_{d, t}=\max \left\{1, r_{T, t}\right\}
$$

In this scenario, neither the nominal reserve nor the deposit rate can turn negative. At the ZLB the central bank has no ability to influence nominal interest rates.

The model is closed with the aggregate resource constraint, given by $y_{t}=c_{t}+i_{t}+g_{t}$, where $g_{t}$ is exogenous government spending. This completes the description of the model. The full list of equilibrium conditions and further definitions can be found in Appendix A.2.

\subsection{Parameterization}

Most features of our parameterization are conventional in that we take standard values from the literature, in particular Primiceri et al. (2006) and Gertler and Karadi (2011). Table 1 documents the baseline parameterization.

Time is quarterly and the subjective discount factor, $\beta$, is 0.99 . For households, we assume $\log$ utility with a consumption habit parameter, $\hbar$, of 0.815 and a Frisch labor supply elasticity of 3.6. The utility weight on labor, $\chi$, is set such that steady state labor supply is normalized to 1 . The two financial sector parameters, $\lambda$ and $\omega$, are calibrated to match a steady state leverage ratio of 4 and a steady state credit spread, $\mathbb{E}_{t} r_{k, t+1}-r_{d, t}$, equal to 100 basis points on an annual basis. The survival probability of bankers, $\theta$, is set to give an average tenure of 10 years.

On the production side, the capital share of intermediate goods firms, $\gamma$, is set to 0.33 and capital depreciates at a fixed rate of $10 \%$ per year. Retail firms face an elasticity of substitution between differentiated goods, $\omega$, equal to 4.167 and on average get to adjust prices every 10 quarters. ${ }^{12}$ When firms cannot adjust prices they are partially

\footnotetext{
12 Note that using a Kimball aggregator as in Smets and Wouters (2007) would have been an alternative to assuming a relatively high degree of price stickiness.
} 
indexed, with $\iota_{p}$ set at 0.241 . Capital goods firms produce new capital subject to quadratic investment adjustment cost characterized by an inverse elasticity of net investment to the price of capital, $\eta$, of 1.728. In terms of policy, we fix the government expenditure share, $g_{t} / y_{t}$, to 0.2 to match consumption and investment expenditure shares in the data. The Taylor-type monetary policy rule has standard coefficients for the response to inflation $\left(\phi_{\pi}=1.5\right)$ and to marginal cost $\left(\phi_{x}=0.125\right)$.

Table 1: Parameters

\begin{tabular}{|c|c|c|c|c|c|}
\hline \multicolumn{6}{|c|}{ Households } \\
\hline$\sigma$ & Risk aversion & 1.000 & $\beta$ & Discount factor & 0.990 \\
\hline$\hbar$ & Habit parameter & 0.815 & $\chi$ & Utility weight on labor & 3.410 \\
\hline & Inverse Frisch elasticity & 0.276 & & & \\
\hline \multicolumn{6}{|c|}{ Financial intermediaries } \\
\hline$\lambda$ & Fraction of divertible assets & 0.381 & $\omega$ & Transfer to new bankers & 0.002 \\
\hline$\theta$ & Survival probability of bankers & 0.972 & $\alpha$ & Reserve-to-deposit ratio & 0.200 \\
\hline \multicolumn{6}{|c|}{ Producers } \\
\hline$\gamma$ & Capital share & 0.330 & $\delta$ & Depreciation rate & 0.025 \\
\hline & Elasticity of substitution & 4.167 & $\iota$ & Probability of fixed prices & 0.900 \\
\hline & Price indexation & 0.241 & $\eta$ & Inverse investment elasticity & 1.728 \\
\hline \multicolumn{6}{|c|}{ Monetary Policy } \\
\hline & Policy rule inflation response & 1.500 & $\phi_{x}$ & Policy rule output response & 0.125 \\
\hline & Policy rule inertia & 0.800 & & & \\
\hline
\end{tabular}

The two remaining structural parameters that deserve particular attention are the policy rule inertial term, $\rho$, and financial intermediaries' reserve-to-deposit ratio, $\alpha$. First, the strength of the signalling channel of negative interest rates will depend sensitively on the degree of monetary policy inertia. In the baseline we set the inertia parameter to $\rho=0.8$. To justify this choice, Figure 2(a) shows estimates of policy inertia for the US, the euro area, and four other countries. Two key messages emerge. First, there is robust evidence for a large inertial component of monetary policy, irrespective of estimation technique or country considered. Second, the range of estimates is from 0.8 (Primiceri et al., 2006, for the US) to 0.96 (Smets and Wouters, 2003, for the euro area). Hence, our baseline value of 0.8 represents a conservative parameterization in terms quantifying the strength of the signalling channel of negative interest rates. ${ }^{13}$

\footnotetext{
${ }^{13}$ Rudebusch $(2002,2006)$ argued that observed policy inertia may, in fact, reflect persistent shocks rather than interest rate smoothing. However, recent work by Coibion and Gorodnichenko (2012) finds strong evidence in favour of the interest rate smoothing explanation.
} 
Figure 2: Monetary policy inertia in the literature and in practice

(a) Estimates of policy rule inertia

\section{United States}

Primiceri et al. (2006)

Smets and Wouters (2007)

Coibion and Gorodnichenko (2012)

Brayton et al. (2014)

Christiano et al. (2014)

\section{United Kingdom}

Burgess et al. (2013)

Switzerland

Rudolf and Zurlinden (2014)
0.80

0.81

0.83

0.85

0.85

0.83

0.90

\section{Euro area}

Smets and Wouters (2003) $\quad 0.96$

Christiano et al. (2010) 0.84

Darracq Pariès et al. (2011) $\quad 0.84$

Coenen et al. (2018) 0.93

Japan

Sugo and Ueda (2007) $\quad 0.84$

Sweden

Adolfson et al. (2008) $\quad 0.88$

Christiano et al. (2011) $\quad 0.82$

Note: Estimates of $\rho$ for a selection of papers and central bank policy models. Brayton et al. (2014) is the Federal Reserve's FRB/US model, Burgess et al. (2013) is the Bank of England's COMPASS model, and Coenen et al. (2018) is the ECB's New Area Wide Model II.

(b) Riksbank repo rate forecasts during negative interest rates

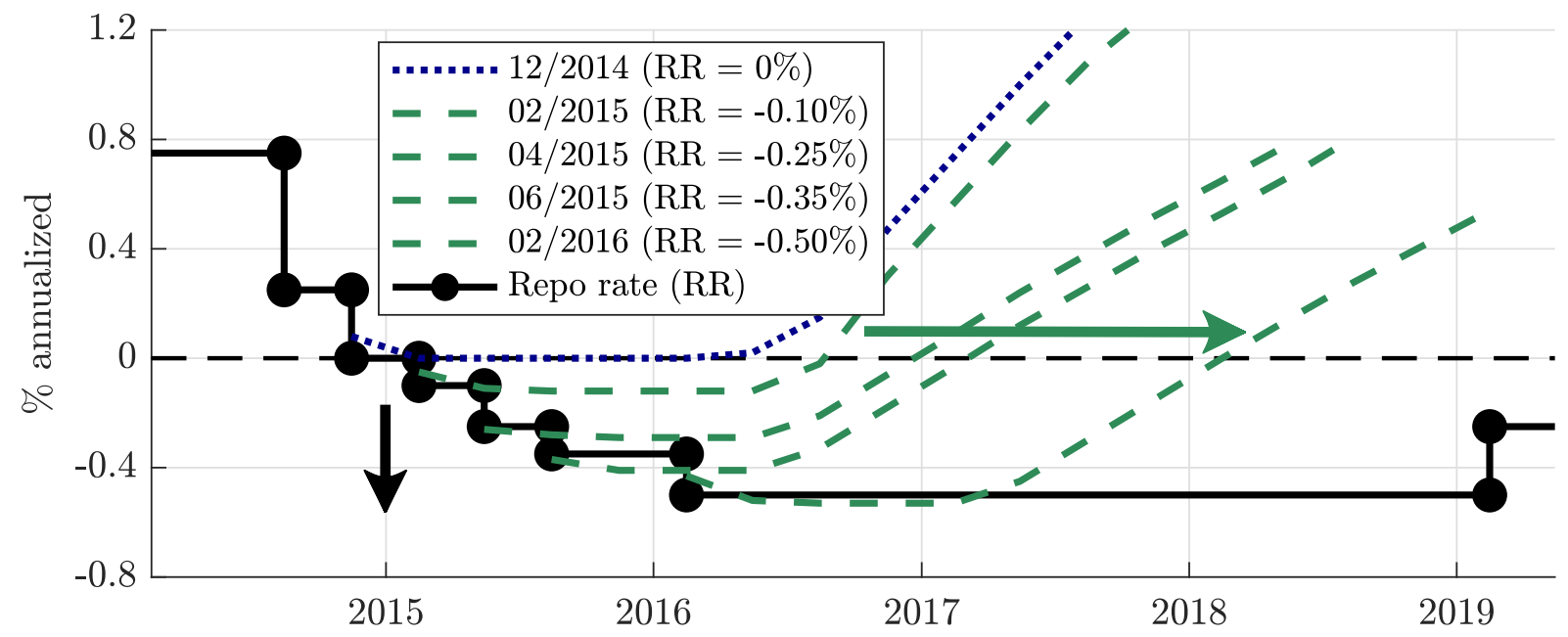

Note: The blue-dot and green-dash lines show the Riksbank's own repo rate forecasts around monetary policy meetings in which they lowered the repo rate, based on quarterly averages. The actual repo rate (black-solid line) is based on daily data. Source: Riksbank monetary policy reports.

One concern might be that the estimates in Figure 2(a) are limited to periods in which policy rates were in positive territory. Figure 2(b) provides suggestive evidence from Sweden that monetary policy inertia extends to negative rate episodes as well. Between February 2015 and February 2016, the Swedish Riksbank lowered the repo rate, its key policy rate, in four steps from $0 \%$ to $-0.5 \%$. Repo rate forecasts published by the Riksbank around the respective monetary policy decisions show that every negative rate decision also came with a substantial downward revision of the forecasted path of the future policy rate, consistent with inertial policy-setting behaviour. 
Second, the strength of the costly interest margin channel of negative interest rates will depend sensitively on the quantity of central bank reserves in the banking system. In the baseline we set the reserve-to-deposit ratio to $\alpha=0.2$. This value is broadly in line with data for both the euro area and the US at the end of 2017. Figure 3 shows the evolution of the euro area and US reserve-to-deposit ratio, respectively. In the aftermath of the financial crisis, total reserve holdings have strongly increased, reflecting banks' desire to hedge against heightened liquidity risk and central banks' willingness to supply additional reserves to the banking system via a range of liquidity and quantitative easing programs. In the euro area, the reserve-to-deposit ratio has risen from a pre-crisis level of around $3 \%$ to a peak of $21.4 \%$ in November 2017. In the US, the reserve-to-deposit ratio rose from a pre-crisis level of around 1\% to a peak of 27.9\% in August 2014, before declining to $19.8 \%$ in November 2017. In Section 3.2 we show results for a sensitivity analysis in which we vary the policy rule inertia, $\rho$, and the reserve-to-deposit ratio, $\alpha$, to study the quantitative importance of both parameters.

Figure 3: Evolution of reserves
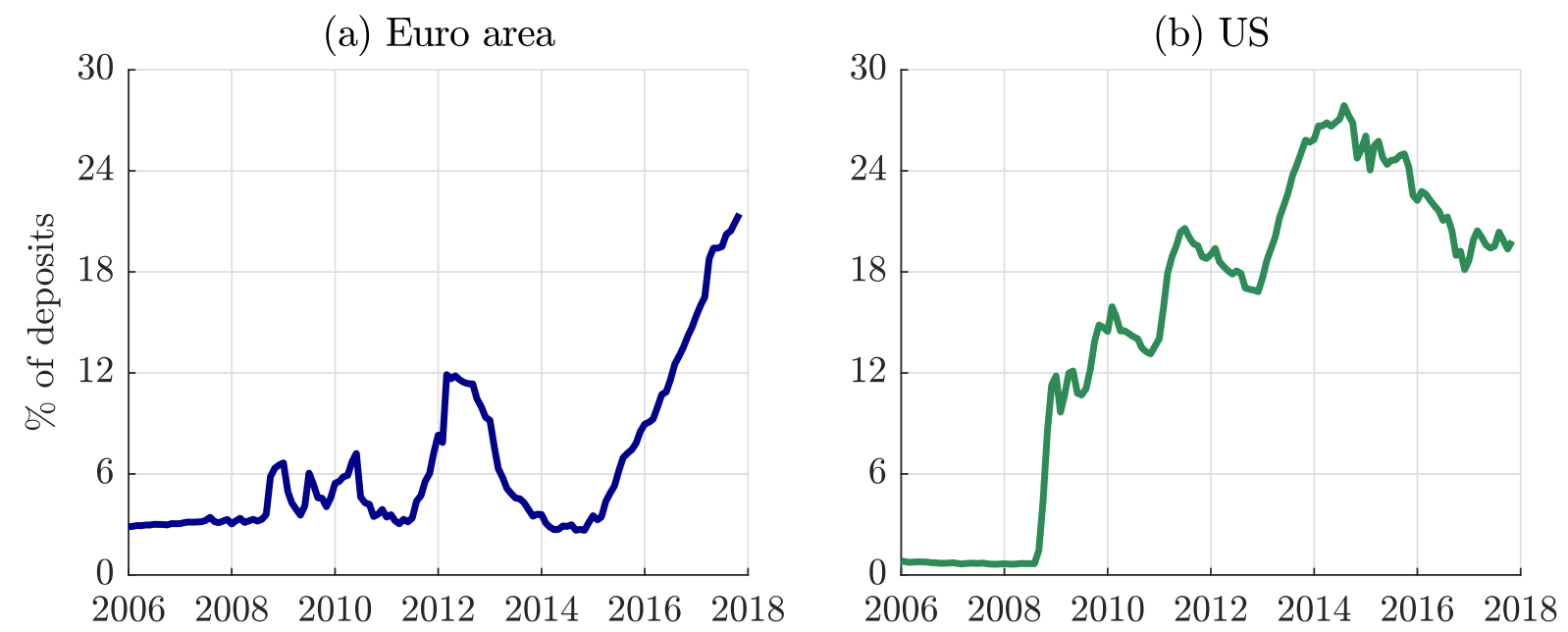

Note: (a) Total reserves of depository institutions over total deposits of households and non-financial corporations; (b) Total reserves of depository institutions over total deposits of commercial banks. Sources: ECB, Federal Reserve Bank of St Louis.

Finally, the model is solved using the OccBin toolbox of Guerrieri and Iacoviello (2015). This is a first-order perturbation method that uses a piecewise approach to account for the occasionally binding ZLB constraint. 


\section{Results}

In this section we present results on the effectiveness of negative interest rates and conduct a sensitivity analysis with respect to the degree of policy inertia $(\rho)$, banks' reserve-todeposit ratio $(\alpha)$, and the ZLB duration. In addition, we provide a novel decomposition of bank net worth to further illuminate the transmission of negative interest rates.

\subsection{Baseline results}

In our baseline experiment we consider a shock to the household discount factor that drives the economy immediately to the ZLB and makes it remain there for 4 quarters when neither the nominal reserve rate nor deposit rates can turn negative (scenario III). ${ }^{14}$ Figure 4 shows impulse responses for our three monetary policy scenarios. In response to the discount factor shock, households become more patient and reduce their consumption. In addition, bank net worth falls, raising credit spreads and lowering investment demand. Thus, the discount factor shock acts as an aggregate demand shock, depressing both output and inflation.

Figure 4: Discount factor shock with inertia in the policy rule
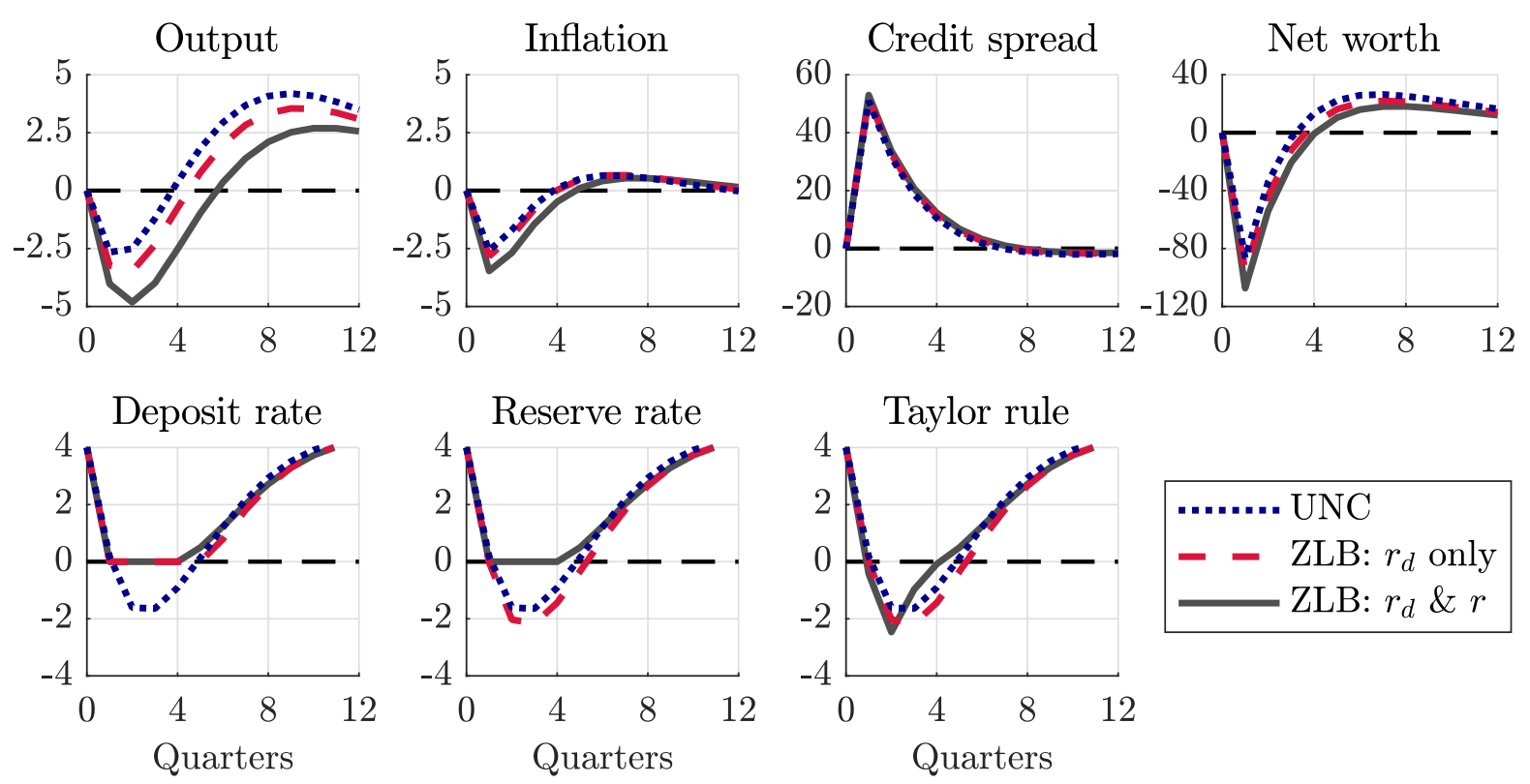

Note: $\alpha=0.2, \rho=0.8$. Impulse responses to a discount factor shock that brings the economy to the ZLB for 4 quarters. All interest rates displayed are in annualized percent. All other variables are in percent deviation from steady state. Inflation is annualized

\footnotetext{
${ }^{14}$ To generate this scenario, we use a $12.5 \%$ rise in the discount factor with an autoregressive parameter of 0.66 . In using a single large shock, we are trading off realism for expositional clarity.
} 
The fall in output (and inflation) in the deposit rate-only ZLB scenario (II, red-dash) as compared to the standard ZLB scenario (III, black-solid) indicates that a negative interest rate policy - at least under our baseline calibration - is expansionary. The unconstrained scenario (I, blue-dot) results in the smallest fall in output. This is when both the deposit and reserve rate mirror the Taylor-type rule implied rate and turn negative in order to partly offset the contraction in output and inflation. When policy is constrained by the ZLB and unable to fully react to the drop in aggregate demand, the fall in output is largest. However, when the central bank can decrease the policy rate into negative territorydespite the deposit rate being bounded by zero - it is able to extend the ZLB duration by 1 quarter and lower the future path of the deposit rate, thus providing additional stimulus. In our baseline experiment, a negative interest rate policy is expansionary even when the relevant rate for agents' intertemporal substitution decision is constrained.

Figure 5: Monetary policy shock with inertia in the policy rule
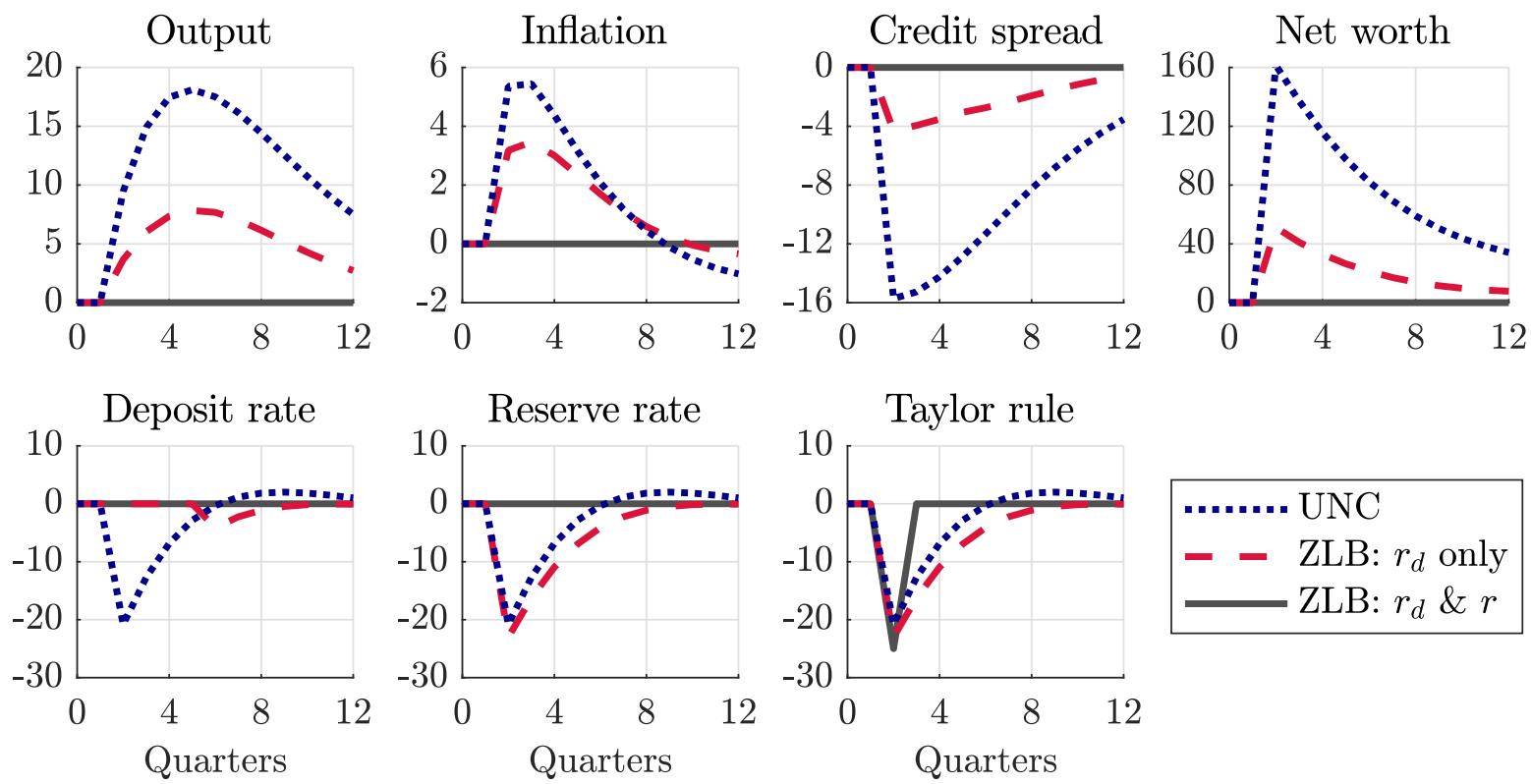

Note: $\alpha=0.2, \rho=0.8$. Impulse responses to a -25 basis point iid monetary policy shock at the ZLB. All interest rates displayed are in annualized basis points. All other variables are in basis point deviation from steady state. Inflation is annualized.

To isolate the quantitative implications of negative interest rates, we introduce a -25 basis point iid monetary policy shock to the economy in period 1 when the economy is at the ZLB. Figure 5 shows the impulse responses to the pure monetary policy shock by stripping out the effect of the underlying discount factor shock. When both the deposit rate and reserve rate are constrained and cannot turn negative, a shock to the Taylor-type rule implied rate has no effect on equilibrium outcomes (III, black-solid). However, allowing for a negative reserve rate (II, red-dash) the monetary policy shock is expansionary and 
the peak output effect is $45 \%$ of an unconstrained monetary policy shock (I, blue-dot). In terms of inflation, negative interest rates are even more effective, with a peak inflation response of $60 \%$ of the unconstrained response. Again, the path of the deposit rate is key to understanding these outcomes. Despite the fact the monetary policy shock occurs in period 1, the deposit rate remains unchanged until period 6 when it drops by 5 basis points and remains persistently below the baseline thereafter.

Figure 6: Monetary policy shock without inertia in the policy rule
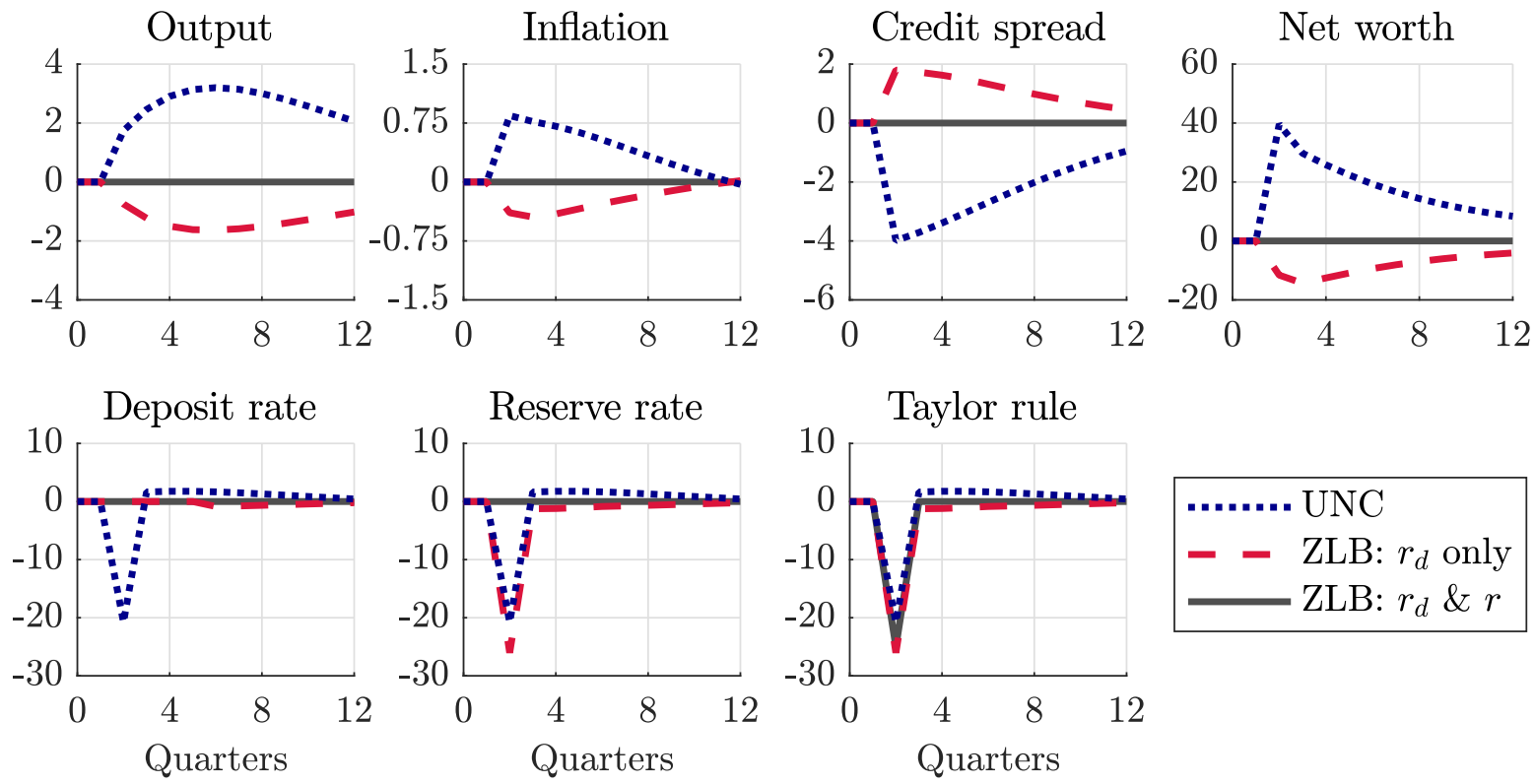

Note: $\alpha=0.2, \rho=0$. Impulse responses to a -25 basis point iid monetary policy shock at the ZLB. All interest rates displayed are in annualized basis points. All other variables are in basis point deviation from steady state. Inflation is annualized.

To explicitly identify the role of the signalling and interest margin channels to which we have eluded frequently, we remove policy inertia and re-run the previous experiment. Figure 6 shows impulse responses to the monetary policy shock at the ZLB with $\rho=0$. The most striking difference (relative to Figure 5) is that under the deposit rate-only ZLB scenario (II, red-dash), negative rates are now contractionary rather than expansionary. The monetary policy easing into negative territory results in a fall in output and inflation. There are two reasons for this. First, by setting $\rho=0$ we have switched off the signalling channel. The fall in the reserve rate has no effect on the path of the deposit rate. Second, the costly interest margin channel results in bank net worth falling. This tightens banks' incentive constraint and causes credit spreads to rise. With the deposit rate constrained, a rise in credit spreads implies a higher lending rate for firms which depresses investment demand. The negative interest rate policy becomes contractionary when the deposit rate is at the ZLB and the drop in the reserve rate is not transmitted via the signalling channel. 
Figure 7: Contribution of signalling and interest margin channels
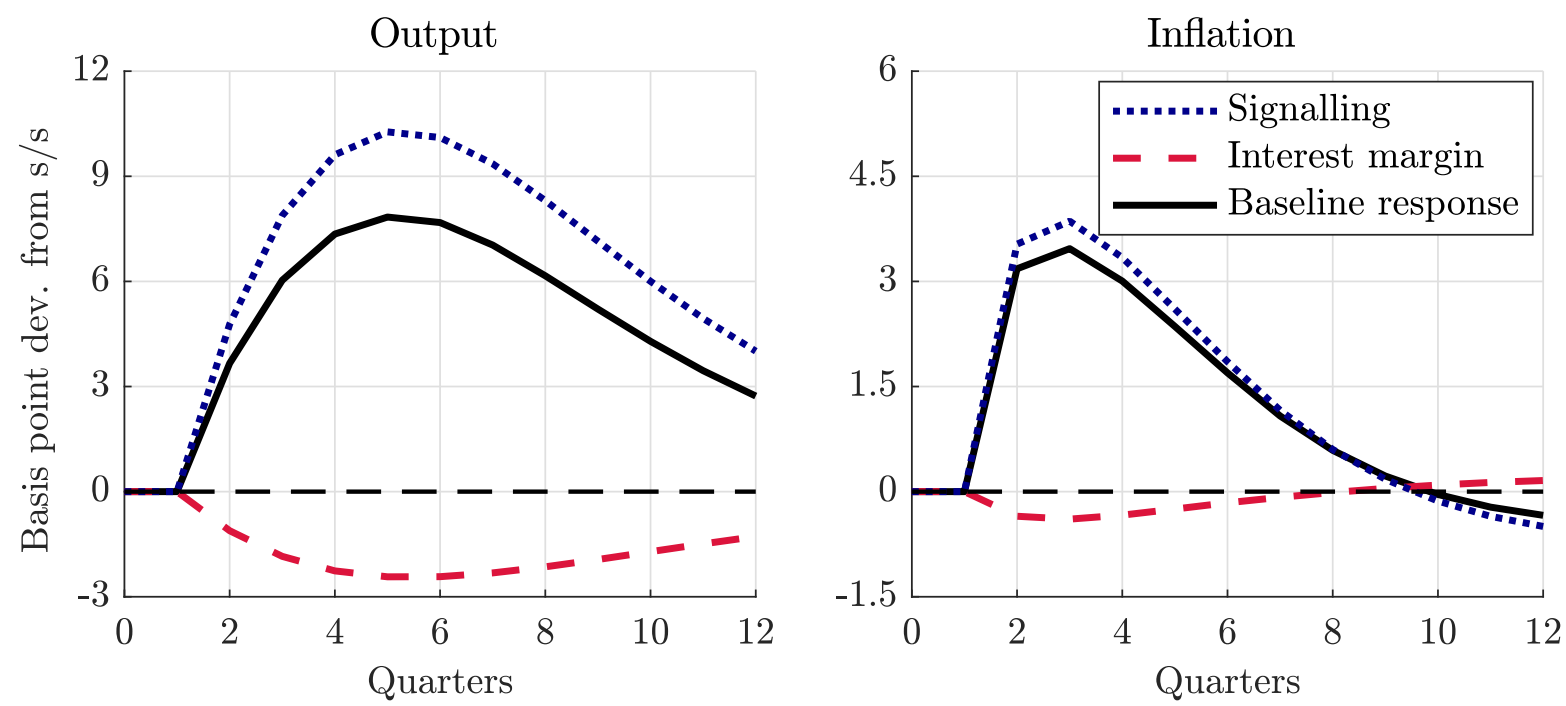

Note: Impulse responses to a -25 basis point iid monetary policy shock at the ZLB. Inflation is annualized. "Signalling" and "Interest margin" plot $\alpha=0$ and $\rho=0$, respectively.

Figure 7 puts these results together and decomposes the output and inflation response to negative interest rates into the signalling channel and costly interest margin channel. The baseline response (black-solid) is equivalent to the deposit rate-only ZLB scenario (II) in Figure 5. Setting $\alpha=0$ and $\rho=0$, respectively, we document impulse responses for a pure signalling (blue-dot) and a pure interest margin channel (red-dash). In the baseline, the peak output response is 8 basis points. The signalling channel thus accounts for 10 basis points while the costly interest margin channel accounts for -2 basis points.

\subsection{Sensitivity analysis}

The previous subsection highlighted that negative interest rates can be both expansionary and contractionary when deposit rates are constrained. In this subsection, we investigate the factors that determine the effectiveness of negative interest rates more thoroughly.

In Figure 8(a) we plot the absolute peak response of output to the 25 basis point iid monetary policy shock at the ZLB for different combinations of policy inertia and sizes of the initial discount factor shock. ${ }^{15}$ The $\mathrm{x}$-axis scales with the size of the initial shock and plots the number of quarters the ZLB is binding. The $y$-axis reports the effectiveness of monetary policy as a percentage of the effect of an unconstrained monetary policy shock.

\footnotetext{
15 To be precise, for an impulse response vector denoted by $\boldsymbol{y}$, where $y_{t}$ is the value of output in period $t$ after the shock, we find $t^{*}$ that is the maximum of $|\boldsymbol{y}|$. We then plot $y_{t^{*}}$ as a percentage of $y_{t^{*}}^{\mathrm{UNC}}$.
} 
This normalization is important because it strips out the effect of any potential forward guidance puzzle in the model. ${ }^{16}$ Comparing Figures 5 and 6 illustrates the need for this. The effect of monetary policy on output in the unconstrained scenario (I), abstracting from ZLB considerations, is heavily dependent on the degree of policy inertia: Changing $\rho=0.8$ to $\rho=0$, the peak output response decreases from 18 to 3 basis points, respectively. To strip out this effect driven by a potential forward guidance puzzle, for the purpose of this sensitivity exercise we do not report the absolute effectiveness of negative interest rates but rather its effectiveness relative to an unconstrained monetary policy shock with the same value of $\rho$. This normalization is also used in Figure 8(b) where we shift the focus to the reserve-to-deposit ratio. In both cases, when the ZLB binds for zero quarters (the model is unconstrained) the value reported is always $100 \%$.

Figure 8: Policy inertia, reserve-to-deposit ratio, and the ZLB
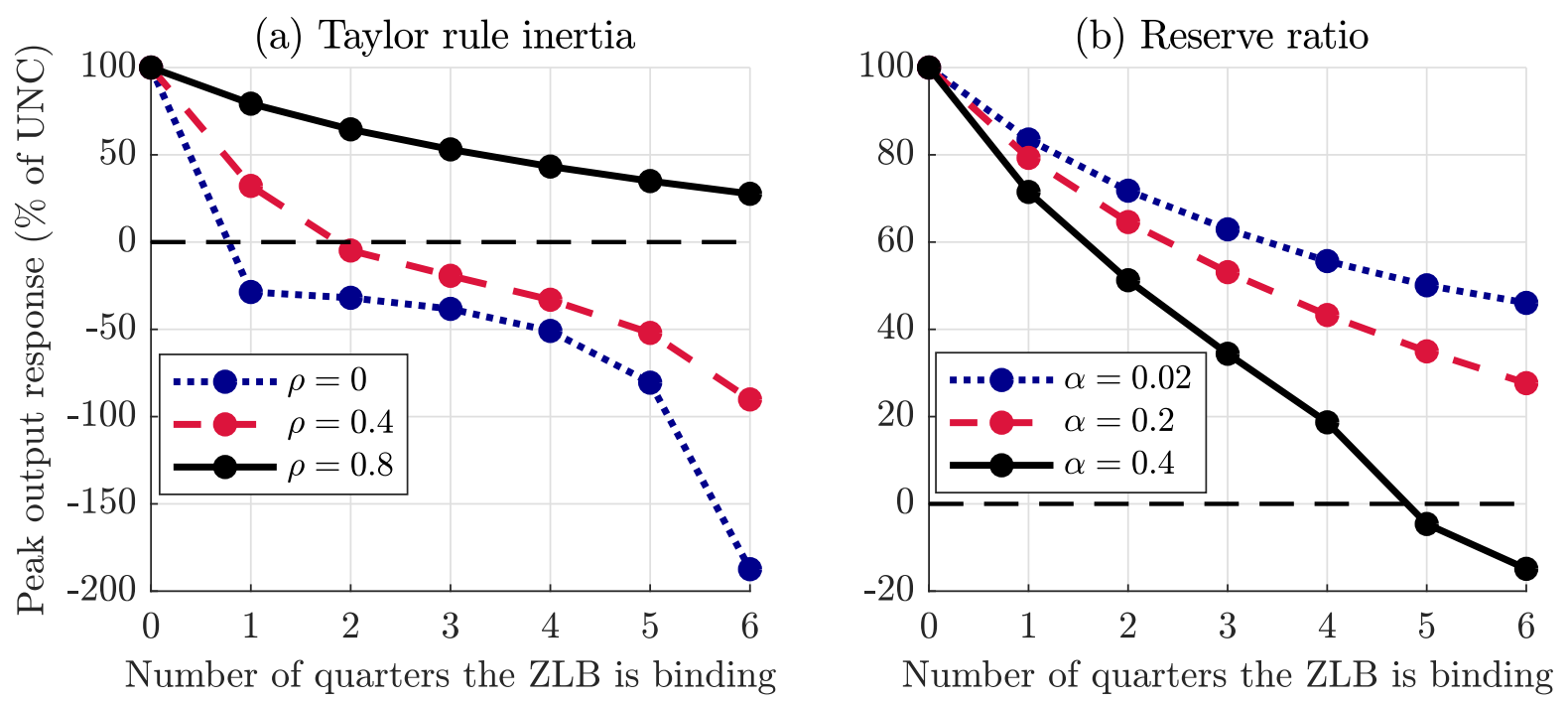

Note: The $\mathrm{x}$-axis scales with the size of the initial discount factor (negative aggregate demand) shock. The $\mathrm{y}$-axis reports the absolute peak response of output to a -25 basis point iid monetary policy shock in period 1 relative the outcome of the unconstrained scenario.

Figure 8(a) offers two important insights. One, negative interest rates are less effective if the ZLB is expected to bind for longer. This is because, if the deposit rate is likely to be constrained at zero for a long period of time, then the effect of lowering the reserve rate by 25 basis points today will have very little effect on the path of the deposit rate. By increasing the severity of the initial discount factor shock (with the ZLB binding for 6 rather than 4 quarters), the effectiveness of negative interest rates drop from $45 \%$ to $30 \%$ of an unconstrained monetary policy easing. Two, a central bank with a lower degree of inertia will find negative interest rates to be less effective. In our model, negative

${ }^{16}$ For a discussion of the forward guidance puzzle, see Del Negro et al. (2012). 
interest rates are only expansionary as a result of signalling a lower expected path of future deposit rates. In fact, once we reduce the degree of inertia to $\rho=0.4$, negative interest rates are only effective in a 1-period ZLB scenario. If instead the ZLB is expected to last for 2 periods, then negative interest rates become contractionary. Without inertia $(\rho=0)$, negative interest rates are contractionary even for a 1-period ZLB scenario.

Figure 8 (b) conducts a similar sensitivity analysis for the size of the reserve-to-deposit ratio. When banks want to hold a higher reserve-to-deposit ratio, this diminishes the positive impact of a negative interest rate policy as the costly interest margin channel is amplified. With inertia in the policy rule held constant at $\rho=0.8$, doubling the amount of reserves banks want to hold to an extreme value of $\alpha=0.4$ results in a contractionary effect of negative interest rates if the ZLB is expected to bind for more than 5 quarters. In this case, the interest margin channel dominates the signalling channel.

The conclusion of this sensitivity analysis is that our baseline finding that negative interest rates are effective is a pretty robust result. Even with $\rho=0.8$ (the lowest degree of policy inertia in Figure 2), $\alpha=0.27$ (the largest reserve-to-deposit ratio in Figure 3), and a severe economic downturn with an expected ZLB duration of 6 quarters, negative interest rates are expansionary in our model.

\subsection{Decomposition of bank profits}

As we have seen by comparing Figure 5 and Figure 6 regarding the effectiveness of negative interest rates with and without policy inertia, the response of bank net worth is a key determinant in the transmission of negative interest rates. In this subsection, we investigate this further by examining a novel decomposition of bank net worth.

We begin by defining bank profits, prof $_{t}$ (the gross growth rate of an individual banker's nominal net worth, conditional on not exiting) - building on Section 2.2-as follows:

$$
\operatorname{prof}_{t}=\left(\pi_{t} r_{k, t}-r_{d, t-1}\right) \phi_{t-1}+r_{d, t-1}-\frac{\alpha}{1-\alpha}\left(r_{d, t-1}-r_{t-1}\right)\left(\phi_{t-1}-1\right) \text {. }
$$

Next, we log-linearize profits and decompose them into 7 distinct terms given by

$$
\begin{gathered}
\hat{\operatorname{prof}}_{t}=\underbrace{\frac{r_{k} \phi}{\text { prof }}\left(\hat{\pi}_{t}-\mathbb{E}_{t-1} \hat{\pi}_{t}\right)}_{\text {Surprise: Inflation }}+\underbrace{\frac{\mathrm{mpk} \phi}{\operatorname{prof}}\left(\mathrm{mpk}_{t}-\mathbb{E}_{t-1} \hat{\mathrm{mpk}}_{t}\right)}_{\text {Surprise: Dividend }}+\underbrace{\frac{\mathrm{mpk} \phi}{\operatorname{prof}}\left(\hat{q}_{t}-\mathbb{E}_{t-1} \hat{q}_{t}\right)}_{\text {Surprise: Capital gain }} \\
+\underbrace{\frac{r_{k} \phi}{\text { prof }} \hat{\operatorname{cs}} \underbrace{}_{t-1}}_{\text {Credit spread }}+\underbrace{\frac{\operatorname{cs} \phi}{\text { prof }} \hat{\phi}_{t-1}}_{\text {Leverage }}+\underbrace{\frac{\operatorname{cs} \phi}{\text { prof }} \hat{r}_{d, t-1}}_{\text {Deposit rate }}-\underbrace{\frac{\alpha}{1-\alpha} \frac{r_{d}(\phi-1)}{\text { prof }}\left(\hat{r}_{d, t-1}-\hat{r}_{t-1}\right)}_{\text {Interest margin channel }},
\end{gathered}
$$


where hats denote log-deviations from steady state, variables without subscripts denote steady states, $\mathrm{cs}_{t} \equiv \pi_{t} r_{k, t}-r_{d, t-1}$ is the nominal credit spread, and $\mathrm{mpk}_{t} \equiv p_{m, t} \gamma y_{t} / k_{t-1}$ is the marginal product of capital. As equation (22) shows, bank profits can be decomposed into three windfall (or "surprise") components and four predetermined components. In general, the return on an asset can be split into a dividend payment and a capital gain, so that, for banks' assets, we term the surprise change in the marginal product of capital as the "dividend" and the surprise change in the price of the asset as the "capital gain". The third surprise component is inflation since we report nominal profits. The four predetermined terms are the evolution of (1) the credit spread, (2) leverage, (3) the riskfree rate, and (4) the partial equilibrium effect of negative rates on interest margins (i.e. the costly interest marginal channel of a negative interest rate policy).

Figure 9: Decomposition of bank profits
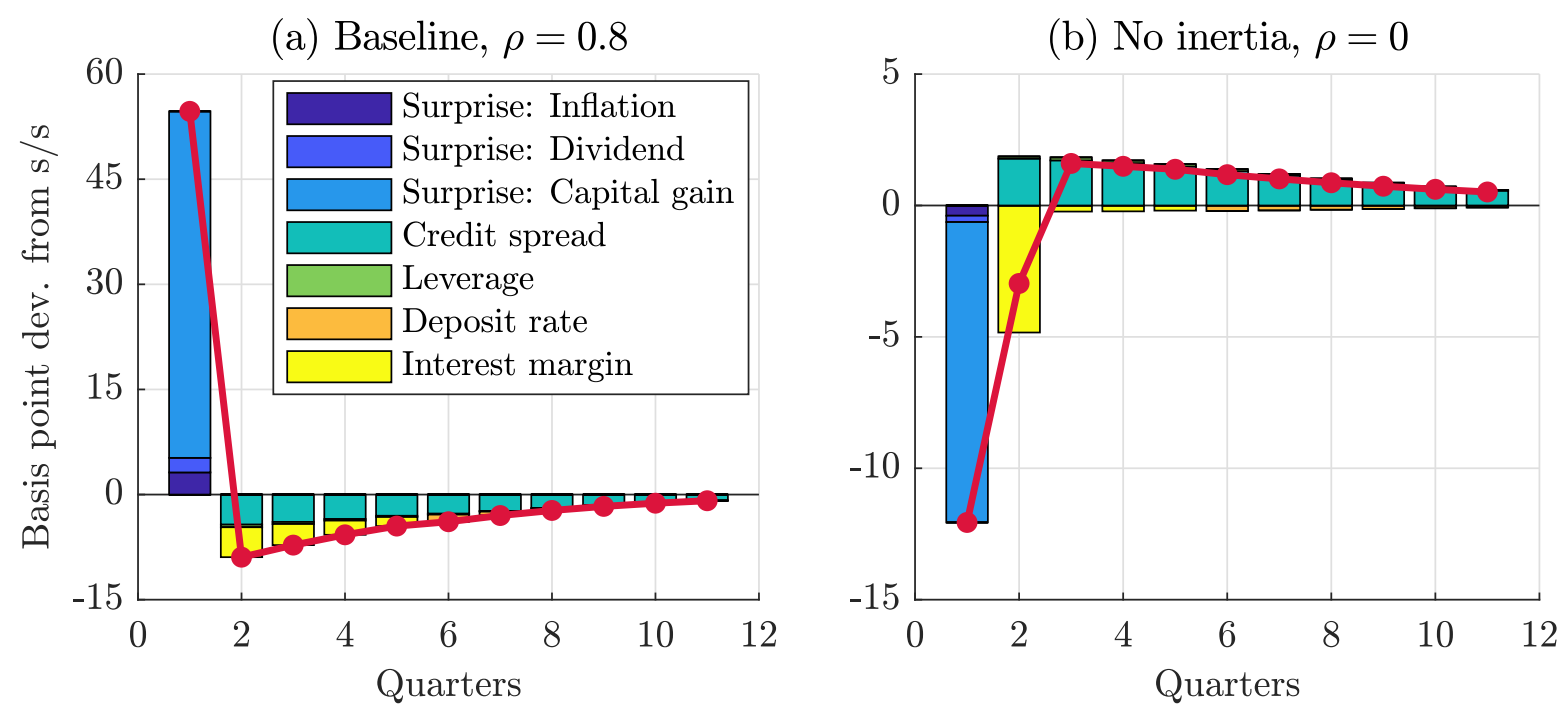

Note: The red-dot line plot the impulse response of bank profits to a -25 basis point iid monetary policy shock at the ZLB. Stacked bars decompose the impulse response for every period.

Figure 9 plots the decomposition of bank profits in response to a -25 basis point iid monetary policy shock at the ZLB with and without policy inertia. In Panel (a), with the signalling channel of negative interest rates switched on, in period 1 we observe a sharp increase in bank profits driven by the three surprise terms from the decomposition. The largest effect on bank profits comes from the capital gain term - that is, a revaluation of the banks' assets in response to the monetary policy shock. With the signalling channel of negative rates in play, a drop of the reserve rate into negative territory depresses the future expected path of deposit rates. Households adjust their intertemporal consumption decision and bring forward consumption demand, aggregate production and the price of capital increase instantaneously, driving up bank profits. From period 2 on, tighter credit 
spreads (the revaluation of bank assets raises net worth, slackens the banks' incentive compatibility constraint, contracting credit spreads) and the costly interest margin channel reduce bank profits, slowly bringing bank net worth back to steady state. This decomposition of how negative interest rates affect different parts of banks' balance sheets is consistent with empirical evidence in, for example, Altavilla et al. (2018).

In Panel (b), with the signalling channel of negative interest rates switched off, bank profits fall in reaction to the negative interest rate policy. Without policy inertia, negative interest rates do not come with an expansionary aggregate demand effect but reduce bank net worth via the costly interest margin channel. Lower bank net worth implies rising credit spreads that affect the decomposition of bank profits in two ways: One, on impact in period 1, higher expected credit spreads depress the investment demand of firms and induce capital losses. Two, from period 2 on, higher realized credit spreads generate additional profits slowly bringing bank net worth back to steady state. Note that compared to Panel (a), most of the partial equilibrium terms have switched sign. The only term which has a consistently negative sign is the interest margin channel. This term reduces bank profits irrespective of the value of $\rho$.

\section{Optimal negative interest rate policy}

Having established the effectiveness of a negative interest rate policy, this section proceeds to study the conditions under which negative interest rates are an instrument in an optimal policymaker's toolkit. We conduct the analysis in a stylized new-Keynesian model which captures the defining features of our main model in the previous section.

In particular, we make use of the canonical 2-equation new Keynesian model augmented with one additional term. The Phillips Curve and IS curve relations are given as follows:

$$
\begin{aligned}
\pi_{t} & =\beta \mathbb{E}_{t} \pi_{t+1}+\kappa \tilde{y}_{t}, \\
\tilde{y}_{t} & =\mathbb{E}_{t} \tilde{y}_{t+1}-\sigma^{-1}\left(r_{d, t}-\mathbb{E}_{t} \pi_{t+1}-g_{t}\right)-\phi\left(r_{d, t}-r_{t}\right),
\end{aligned}
$$

where variables are given in log-levels, $\tilde{y}_{t}$ is the output gap, and $\phi\left(r_{d, t}-r_{t}\right)$ captures, in reduced form, the effect of the costly interest margin channel on aggregate demand. The only source of uncertainty is the natural real rate process, $g_{t}$, which has a steady state $g=\log (\beta)$. In addition, the policymaker faces three constraints given by

$$
r_{d, t} \geq 0, \quad r_{d, t}-r_{t} \geq 0, \quad r_{d, t}\left(r_{d, t}-r_{t}\right)=0
$$


The first constraint in (25) is the ZLB on the deposit rate. The second constraint states that the deposit rate faced by households cannot be below the central bank's reserve rate, and the third constraint ensures that the reserve and deposit rate can only diverge when the deposit rate is at zero. Thus, in this formulation, the policymaker controls the interest rate on reserves, $r_{t}$, which, unlike the interest rate on deposits, can turn negative. In normal times, an arbitrage condition equates the two rates. However, if the reserve rate turns negative, banks experience a fall in their interest margin, captured by $\phi\left(r_{d, t}-r_{t}\right) .{ }^{17}$

Social welfare is derived from a second-order approximation of the representative household's expected lifetime utility and is given by

$$
V_{t}^{S W}=-\frac{1}{2}\left(\pi_{t}^{2}+\lambda \tilde{y}_{t}^{2}\right)+\beta \mathbb{E}_{t} V_{t+1}^{S W}
$$

We choose to use this stylized model for two reasons. One, we solve for discretionary optimal policy and this involves derivatives of policy functions. The solution technique adopted in the previous section, however, solves for perfect foresight paths rather than policy functions. As a result, it is not feasible for this problem. We instead need to use a global solution method. This, however, constrains the size of the model in terms of state variables. One natural simplification of our main model would be to remove endogenous capital formation. This is done by, for example, de Fiore and Tristani (2013) and de Paoli and Paustian (2017), who study the optimal policy implications of financial frictions. However, removing endogenous capital formation fundamentally changes the nature of financial frictions. In our main model, a widening credit spread acts like an aggregate demand shifter, lowering both output and inflation. This is the motivation for the additional term $\phi\left(r_{d, t}-r_{t}\right)$ we introduce in equation (24). In a model without endogenous capital formation, a widening of the credit spread acts like a cost-push shock, lowering output but raising inflation through a rise in marginal cost. Thus, simplifying the model in this way would fundamentally alter the behaviour of our model.

Two, optimal policy in large-scale models can often be problematic. Since the model contains many wedges the policymaker wants to minimize, optimal policy can result in a very erratic interest rate path. As a result, central bank practitioners often introduce an ad hoc smoothing term into the loss function to remove frequent policy reversals. However, the effect of delegation of policy to a policymaker with a preference for smoothing is a key feature we study. In addition, optimal policy in the canonical new-Keynesian model, with and without the ZLB, is already well understood in the literature. Its simplicity allows for analytical results and is a useful framework for our analysis of negative interest rates.

\footnotetext{
17 The assumption that the reduced form term that captures the costly interest margin channel is linear is in line with the dynamics observed in the fully micro-founded model from the previous section.
} 


\subsection{Analytical results}

We begin by considering the commitment solution of the optimal policymaker and derive the following proposition:

Proposition 1 Under commitment-when the policymaker solves for a state-contingent plan $\left\{\pi_{t}, \tilde{y}_{t}, r_{t}, r_{d, t}\right\}_{t=0}^{\infty}$ maximizing (26) subject to the sequence of constraints (23) - (25) it holds that $r_{t} \geq 0$.

Proposition 1 states that with full commitment, a policymaker would never use negative interest rates. A proof of Proposition 1 is given in Appendix B.1. The intuition, however, is relatively simple. Under commitment, the central bank can credibly promise to hold the deposit rate lower-for-longer in the future in order to compensate, in part, for the presence of the ZLB. Thus, setting a negative reserve rate results in a cost via the interest margin channel without any additional benefit. Next, we consider the optimal discretionary solution of the central bank and derive the following proposition:

Proposition 2 Under discretion - when the policymaker solves for $\left\{\pi_{t}, \tilde{y}_{t}, r_{t}, r_{d, t}\right\}$ to reoptimize (26) every period subject to (23) - (25) and the actions of future policymakersit holds that $r_{t} \geq 0$.

Proposition 2 states that negative interest rates are also not part of the optimal timeconsistent policymaker's toolkit. A proof of Proposition 2 is given in Appendix B.2. Under discretion, the policymaker cannot commit to future actions and so a negative interest rate has no ability to signal. Thus, setting a negative reserve rate results in a cost via the interest margin channel without any benefits. There are, however, conditions under which negative interest rates can be part of an optimal policymaker's toolkit. These are given in the our final proposition:

Proposition 3 Two necessary conditions for the optimality of negative interest rates are i) a discretionary policy setting, and ii) the delegation of policy to a policymaker with a preference for smoothing interest rates.

We prove Proposition 3 by non-linearly solving a calibrated example in Section 4.2 below. Table 2 summarizes all three propositions.

Table 2: Optimality of negative interest rates

\begin{tabular}{|rcc|}
\hline & Commitment & Discretion \\
Smoothing & $\times$ & $\checkmark$ \\
No Smoothing & $\times$ & $\times$ \\
\hline
\end{tabular}




\subsection{A calibrated example}

To demonstrate the optimal use of negative interest rates in an environment where the policymaker has a preference for interest rate smoothing and optimizes under discretion, we consider a central bank loss function given by

$$
V_{t}=-\frac{1}{2}\left((1-\psi)\left(\pi_{t}^{2}+\lambda \tilde{y}_{t}^{2}\right)+\psi\left(r_{t}-r_{t-1}\right)^{2}\right)+\beta \mathbb{E}_{t} V_{t+1},
$$

with an explicit preference for interest rate smoothing weighted by $\psi \cdot{ }^{18}$ When $\psi=0$, the policymaker's objective function matches the social welfare function. The discretionary policymaker reoptimizes every period, taking the policy functions of future policymakers as given. When $\psi>0, r_{t-1}$ becomes an endogenous state variable making negative interest rates a tangible signal of future interest rates in a time-consistent equilibrium.

Maximizing (27) subject to (23) - (25), the first-order conditions can be written as follows (where the form of the equilibrium conditions depends on the "regime" $r_{t}$ is in):

$$
\begin{aligned}
& \text { Regime I: }\left(r_{t}>0\right) \\
& 0=\psi(1+\beta) r_{t}-\psi r_{t-1}-\psi \beta \mathbb{E}_{t} r_{t+1}+(1-\psi) \beta \mathbb{E}_{t} \frac{\partial \pi\left(r_{t}, g_{t+1}\right)}{\partial r_{t}} \\
& +(1-\psi)\left(\mathbb{E}_{t} \frac{\partial y\left(r_{t}, g_{t+1}\right)}{\partial r_{t}}+\sigma^{-1} \mathbb{E}_{t} \frac{\partial \pi\left(r_{t}, g_{t+1}\right)}{\partial r_{t}}-\sigma^{-1}\right)\left(\lambda \tilde{y}_{t}+\kappa \pi_{t}\right), \quad r_{d, t}=r_{t} . \\
& \text { Regime II }\left(r_{t}<0\right) \\
& 0=\psi(1+\beta) r_{t}-\psi r_{t-1}-\psi \beta \mathbb{E}_{t} r_{t+1}+(1-\psi) \beta \mathbb{E}_{t} \frac{\partial \pi\left(r_{t}, g_{t+1}\right)}{\partial r_{t}} \\
& +(1-\psi)\left(\mathbb{E}_{t} \frac{\partial y\left(r_{t}, g_{t+1}\right)}{\partial r_{t}}+\sigma^{-1} \mathbb{E}_{t} \frac{\partial \pi\left(r_{t}, g_{t+1}\right)}{\partial r_{t}}+\phi\right)\left(\lambda \tilde{y}_{t}+\kappa \pi_{t}\right), \quad r_{d, t}=0 . \\
& \text { Regime III: }\left(r_{t}=0\right) \\
& r_{t}=r_{d, t}=0,
\end{aligned}
$$

where $\tilde{y}_{t}=y\left(r_{t-1}, g_{t}\right)$, for example, denotes the policy function for the output gap as a function of the state vector, $\left(r_{t-1}, g_{t}\right)$. For a given state vector, the economy can be in three possible regimes: I: The ZLB is not binding, II: The ZLB on the deposit rate is binding and the reserve rate is set negative, or III: The ZLB is binding and the reserve rate is also set to zero. Regime III allows for the possibility that, even though negative interest rates are feasible, the policymaker may choose not to make use of them.

\footnotetext{
18 There exists an extensive literature on why, with discretion, it can be beneficial to delegate policy to a policymaker with a loss function that deviates from the social welfare function. Woodford (2003) shows - even in the absence of the ZLB - delegation to a policymaker with a preference for smoothing is desirable. Nakata and Schmidt (2019) show that the benefit of a policymaker with a preference for smoothing is even greater when the ZLB occassionally binds.
} 
For example, we will see that if $\psi$ is sufficiently small or $\phi$ is sufficiently large, then regime II is never visited and at the ZLB, the reserve rate is always set to zero. The first-order condition clarifies the role of policy smoothing in generating the signalling channel. When $\psi=0$, it reduces to a static condition: $0=\lambda \tilde{y}_{t}+\kappa \pi_{t}$. When $\psi>0$, the policymaker takes account of the actions of future policymakers and past actions influence current decisions.

Table 3: Parameters

\begin{tabular}{llrrlr}
\hline \hline$\sigma$ & Risk aversion & 0.500 & $\beta$ & Discount factor & 0.990 \\
$\kappa$ & Phillips curve slope & 0.008 & $\phi$ & Cost of negative rates & 0.200 \\
& & & & & \\
$\lambda$ & Weight on output gap & $7.85 \times 10^{-4}$ & $\psi$ & Weight on policy smoothing & 0.029 \\
\hline
\end{tabular}

We solve the model using the Endogenous Grid Method of Carroll (2006). ${ }^{19}$ Our parameterization follows Nakata and Schmidt (2019), given in Table 3. The weight on policy smoothing, $\psi$, is the value that maximizes the social welfare function in the absence of negative interest rates as a policy tool (Nakata and Schmidt, 2019, Table 2, pp 187). The cost parameter, $\phi$, is set to 0.2 . This implies that, all else equal, a 25 basis point gap between the deposit and reserve rate widens the output gap by 5 basis points. The natural real rate, $g$, follows an $\mathrm{AR}(1)$ process with persistence 0.85 and standard deviation 0.04. We approximate the process using Tauchen and Hussey (1991)'s quadrature algorithm with 21 grid points. The details of the solution algorithm are described in Appendix B.3.

Figure 10 provides several useful insights into the optimal discretionary policy solution with smoothing. Panel (a) plots policy functions for the reserve rate, $r_{t}$, as a function of the endogenous state variable, $r_{t-1}$, for selected values of $g_{t}$. The shape of the policy functions are notable for two reasons. First, the policy functions turn negative, suggesting that the optimal policymaker, under this parameterization, is willing to use negative interest rates under certain conditions. This proves Proposition 3. Second, there are regions of "inaction" where the policy functions are horizontal. That is, there is a region of the state variable, $r_{t-1}$, where for a given fall in $g_{t}$, the policymaker initially drops the reserve rate to zero and only in subsequent periods lowers the reserve rate into negative territory. Furthermore, to the left of the inaction region, the slope of the policy function is steeper than to the right of the inaction region. That is to say, once the policymaker passes the threshold into negative territory, it will continue cutting the reserve rate more aggressively than if unconstrained by the ZLB.

\footnotetext{
19 Blake and Kirsanova (2012) warn that optimal discretionary policy in a linear-quadratic rational expectations model can yield multiple equilibria. In extensive numerical testing we have not come across multiple equilibria for our model, but we cannot rule out their existence.
} 
Panels (b) and (c) display the ergodic distributions (in green) for $r_{t}$ and $r_{d, t}$, respectively, to highlight the effect of this inaction. The ergodic distribution of the deposit rate is naturally truncated by the ZLB. The ergodic distribution of the reserve rate has a non-trivial mass below zero. However, in line with the observed inaction, the ergodic distribution is not symmetric. First, there is additional mass around $r_{t}=0$. Second, there is additional mass for $r_{t}<0$ relative to the distribution without the ZLB constraint (red line).

Comparing ergodic distributions with and without negative interest rate policies, we further find that without the use of negative rates, the ZLB on deposit rates is expected to bind $3.7 \%$ of the time compared to the higher frequency of $4.4 \%$ when negative rates are used. The benefits of this increased frequency at the ZLB becomes clear in the next exercise. In terms of welfare, in the absence of negative interest rates, the household would forgo $2.57 \%$ of consumption per period to avoid uncertainty. Allowing for a negative interest rate policy reduces this value to $2.33 \%$. Thus, the addition of negative rates into the policymaker's toolkit can generate a small but meaningful improvement in welfare. ${ }^{20}$

Figure 10: Optimal policy solution
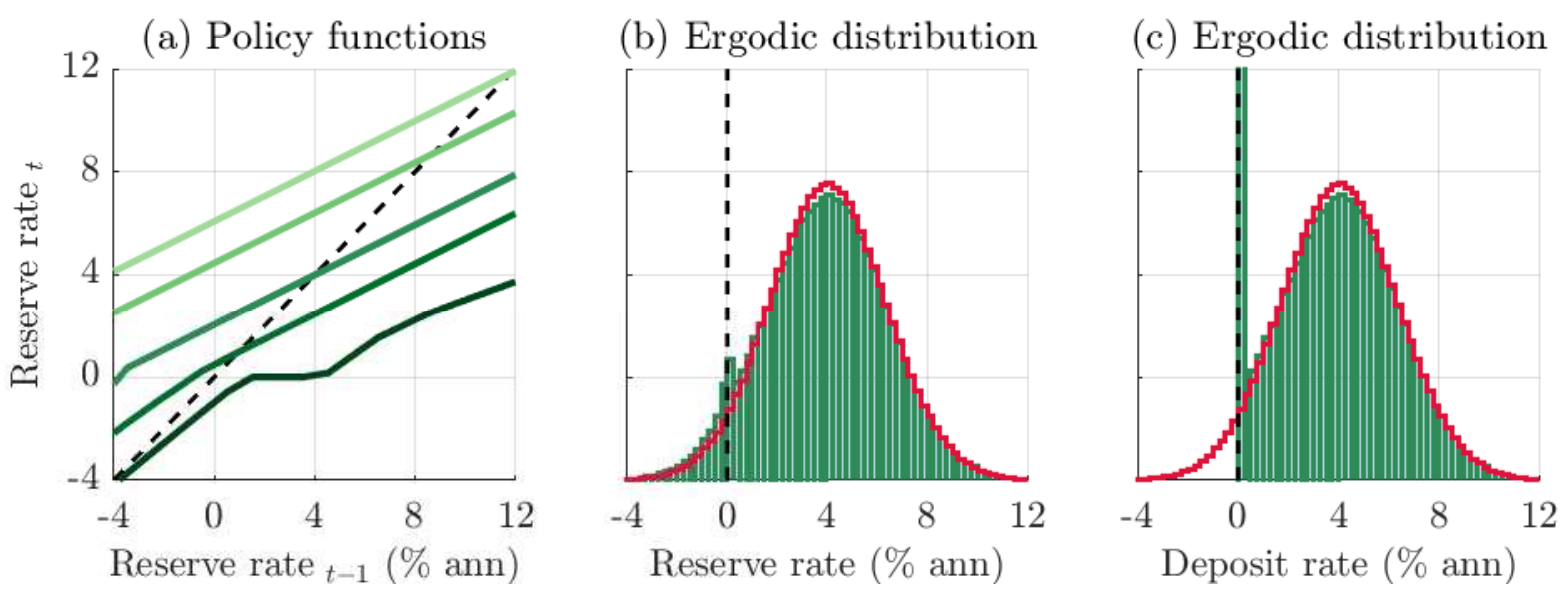

Note: (a) plots policy functions for five different $g$ values. The black-dash is the 45 -degree line. (b) and (c) plot ergodic distributions generated from simulations of length $10^{6}$ with a burn-in of length $10^{3}$. The filledgreen plots the distribution with negative rates, the red line the distribution without a ZLB constraint.

Figure 11 shows the benefits of negative interest rates in an experiment in which the natural real rate, $g_{t}$ drops into negative territory and remains at the level for 3 quarters before jumping back to steady state. For comparison, we plot three lines. The red-dash line is our baseline parameterization. The black-solid line is the equilibrium outcome when the policymaker is not able to set a negative reserve rate (or, equivalently, when

\footnotetext{
${ }^{20}$ Appendix B.4 derives the consumption equivalent welfare measure and plots welfare against different values of the smoothing parameter, $\psi$ (Figure B.1).
} 
the cost of negative interest rates is sufficiently high - in this case $\phi>0.35$ - such that the policymaker chooses not to use negative interest rates). The green-dotted line plots an extreme scenario where there is no cost of negative interest rates $(\phi=0)$.

When $\phi>0.35$, the policymaker behaves as if there was a ZLB on the reserve rate. The nominal reserve rate is lowered to the ZLB, but this easing does not generate a sufficient fall in the real deposit rate, $r_{d, t}-\mathbb{E}_{t} \pi_{t+1}$, to offset the fall in $g_{t}$. As a result, inflation falls and the output gap opens. In contrast, when $\phi=0.2$ the policymaker gradually lowers the reserve rate into negative territory, reaching $-1.2 \%$ in period 4 . Although the deposit rate remains bounded by zero, this negative reserve rate ensures that the deposit rate is lower after period 4 than without negative interest rates. This lower path for the deposit rate allows inflation to overshoot after $g_{t}$ is back at steady state, also lowering the expected real deposit rate in early periods. As a consequence the drop in inflation and the widening of the output gap is less severe. The scenario without the cost of negative rates $(\phi=0)$ shows the maximum impact of negative interest rates. In this case, the reserve rate reaches $-3.8 \%$ in period 2 and the deposit rate is a full 1 percentage point lower in period 6 than in the case without negative rates. The drop in the output gap and inflation is much less pronounced than in the other two scenarios. ${ }^{21}$

Figure 11: Optimal policy scenarios
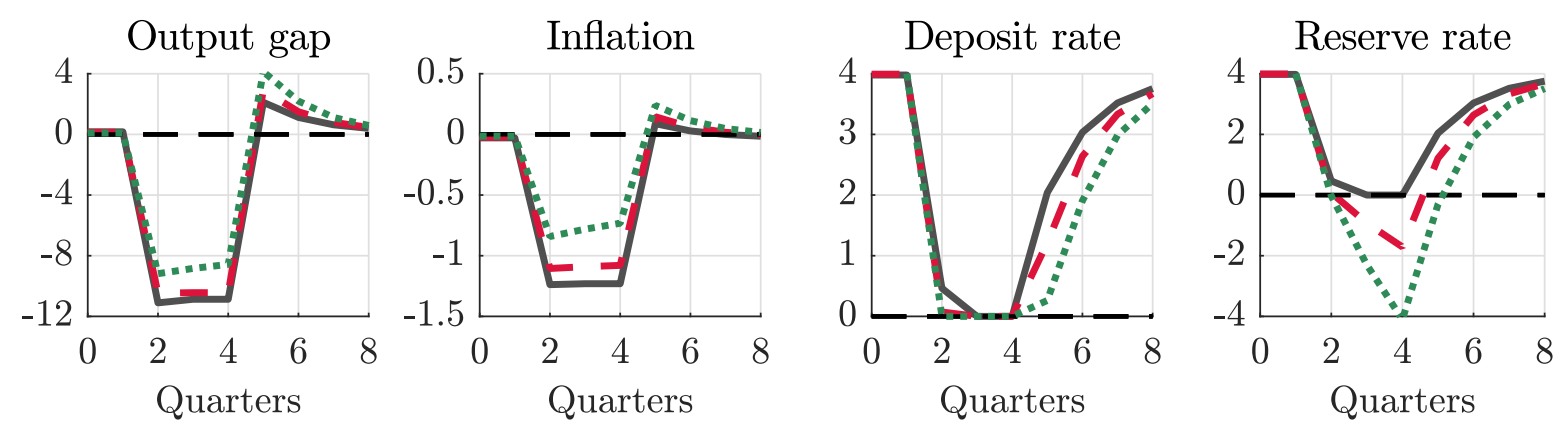

$\because \cdots \cdots \phi=0 \quad-\quad-\phi=0.2 \quad \phi>0.35$

Note: Impulse responses to a drop in $g_{t}$ into negative territory for 3 quarters before jumping back to its steady state value. The output gap is measured in percent. Inflation is in annualized percent deviation from steady state. The deposit and reserve rates are in levels, annualized.

\footnotetext{
21 This exercise illustrates that the increased frequency at the ZLB arises for two reasons: First, is the standard reason that signalling with negative rates keeps the deposit rate "lower for longer" at the ZLB in the event of a contractionary shock. Second, on the impact of a shock a policymaker with access to negative interest rates is willing to cut the policy rate faster. Observe that, due to smoothing, the black-solid line does not reach the ZLB until period 3 since the benefit of cutting the period-2 policy rate further is outweighed by the cost in terms of smoothing rates. In contrast, the red-dash and green-dot lines that describe negative rate scenarios reach the ZLB in period 2.
} 


\subsection{Comparative statics}

In this section, we study comparative statics on how negative the policymaker is willing to set the reserve rate across the parameter range. The aim is once again for qualitative insights rather than quantitative predictions. We do this in the following way: First, we set the natural rate shock, $g_{t}$, to be iid. Second, we presume that the policymaker disregards the output gap $(\lambda=0)$ and only cares about smoothing interest rates between periods 2 and 1 . These two assumptions effectively reduce the model to a 2-period problem since $\left\{\pi_{t}, \tilde{y}_{t}\right\}=\{0,0\}$ for $t \geq 3$, allowing for closed-form solutions, given in Appendix B.5. In order to highlight the trade-offs at play for the policymaker, we start from an extreme parameterization with $\psi$ scaled down by 50 and and $\phi$ scaled up by 5 .

Figure 12: Optimal policy sensitivity analysis

(a) Policy smoothing

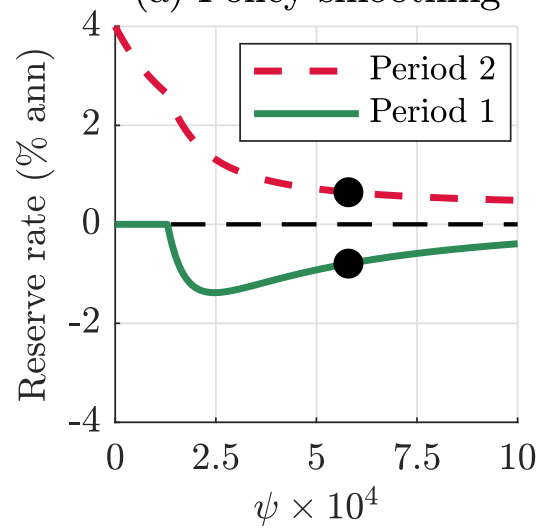

(b) Cost of neg rates

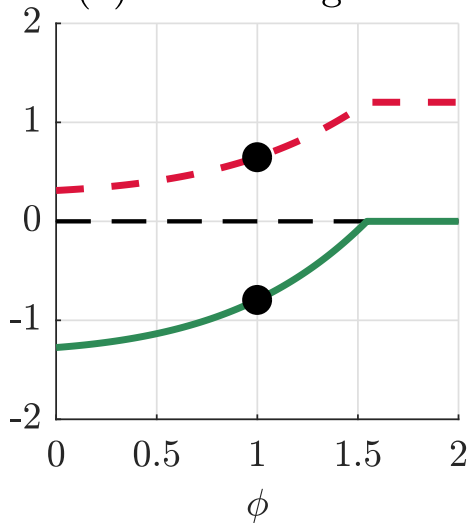

(c) Shock size

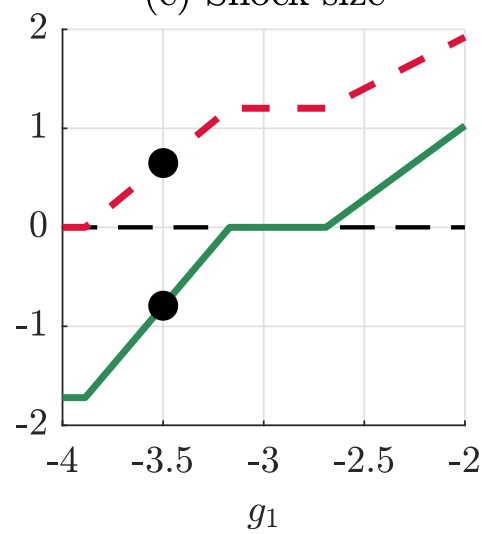

Note: The black-dot refers to the baseline parameterization across the three panels, where, relative to Table $3, \psi=\psi / 50$ and $\phi=\phi \times 5$. The natural real rate, $g_{1}$, is set to -3.5 .

Figure 12 illustrates the comparative statics effects of varying $\psi$ and $\phi$ on $r_{1}$ and $r_{2}$ when the natural real rate in period 1 is $-3.5 \%$ (Panel (c) varies the severity of the scenario by varying the natural real rate, $g_{1}$ ). In Panel (a), we vary the smoothing parameter, $\psi$. The value of $\psi$ has a non-monotonic effect on the optimal period-1 reserve rate. When $\psi=0$, the policymaker is unable to signal and thus does not use negative interest rates. Also for small positive smoothing values, the signalling benefit is outweighed by the cost of negative rates and the reserve rate remains at zero. Once the smoothing parameter becomes sufficiently large, however, the signalling channel of negative interest rates dominates the cost channel and a negative interest rate policy becomes optimal. In this simplified model, with $r_{d, 1}$ constrained at zero, the only benefit of lowering $r_{1}$ for period-1 inflation, $\pi_{1}$, is to lower $r_{2}$ and thus raise period-2 inflation, $\pi_{2}$, which lowers the period-1 real interest rate. When $\psi$ is small the policymaker sets a very negative interest rate in order to induce a 
lowering of $r_{2}$. However, as $\psi$ rises, the signalling channel becomes more powerful and the policymaker need not set such a negative rate to achieve the same fall in $r_{2}$. Thus, we end up with a non-monotonic result in which both policymakers with very low and very high smoothing preferences make very little use of negative interest rates, while policymakers with an intermediate smoothing preference optimally set a very negative reserve rate.

In Panel (b), we vary the cost parameter, $\phi$. In this case, $r_{1}$ is increasing in the $\phi$, which is not a surprise. However, the relationship is nonlinear and convex. Starting from $\phi=0$, a marginal increase in the cost parameter has only a small effects on the equilibrium decision of the policymaker, but as $\phi$ increases, the policymaker rapidly reduces how negative it is willing to set the reserve rate. As we increase $\phi$ further, there comes a point at which the cost of setting a negative interest rate outweighs the benefit in terms of signalling. At this point negative interest rates are no longer optimal, and the policymaker sets $r_{1}=0$.

Finally, in Panel (c) we vary the size of the natural real rate shock, $g_{1}$. Starting from the right, and looking left as we increase the size of the shock, the policymaker naturally lowers the policy rate in order to accommodate the shock. However, we again observe a region of inaction in which, for a natural real rate between $-2.8 \%$ to $-3.4 \%$, the policymaker does not engage in setting a negative rate. However, when the shock is sufficiently large the policymaker begins using negative interest rates and with a slope $\left(\partial r_{1} / \partial g_{1}\right)$ that is steeper than to the right of the inaction region, similar to our finding in Figure 10.

\section{Conclusion}

Negative interest rates are a new, albeit controversial monetary policy tool. This paper studies a novel signalling channel of negative interest rates and asks whether they can be 1) an effective and 2) an optimal monetary policy tool. To the former we provide strong evidence that in a carefully calibrated medium-scale new-Keynesian model, the answer is likely yes. For the majority of the parameter space, the signalling channel dominates the costly interest margin channel. This exemplifies the importance of taking into account general equilibrium effects and cautions against partial equilibrium views of policy actions. In countries in which the central bank has adopted a negative interest rate policy, many commercial banks have been vocally critical about the contractionary effects on their net interest margins and profits. However, as we demonstrate, negative interest rates - via policy signalling - have potentially large beneficial general equilibrium effects for banks' asset values and balance sheet health not obviously attributable to the actions of the central bank. 
One may be concerned that the above result relies heavily on inertia in a non-optimized, estimated policy rule. In the latter part of the paper, we take an optimal policy approach and prove conditions under which negative interest rates are (not) part of an optimal policymaker's toolkit. We prove that negative rates are redundant when the policymaker has full commitment. This, however, is unlikely to be a reasonable description of the reality. We show that (under more realistic conditions) in which central banks do not have full commitment but have a preference for policy smoothing then negative interest rates can be a welfare improving policy tool. 


\section{References}

Adolfson, M., S. Laséen, J. Lindé, And M. Villani (2008): "Evaluating an Estimated New Keynesian Small Open Economy Model," Journal of Economic Dynamics and Control, 32, 2690-2721.

Altavilla, C., M. Boucinha, And J.-L. Peydró (2018): "Monetary Policy and Bank Profitability in a Low Interest Rate Environment," Economic Policy, 531-586.

Bhattacharya, S. (1979): "Imperfect Information, Dividend Policy, and 'The Bird in the Hand' Fallacy," Bell Journal of Economics, 10, 259-270.

Bhattarai, S., G. B. Eggertsson, And B. Gafarov (2015): "Time Consistency and the Duration of Government Debt: A Signalling Theory of Quantitative Easing," NBER Working Paper Series, 21336.

Bianchi, J. And S. Bigio (2018): "Banks, Liquidity Management and Monetary Policy," Unpublished Manuscript.

Blake, A. P. And T. Kirsanova (2012): "Discretionary Policy and Multiple Equilibria in LQ RE Models," Review of Economic Studies, 79, 1309-1339.

Brayton, F., T. Laubach, and D. Reifschneider (2014): "The FRB/US Model: A Tool for Macroeconomic Policy Analysis," FEDS Notes. Board of Governors of the Federal Reserve System.

Brunnermeier, M. K. And Y. Koby (2018): "The Reversal Interest Rate," NBER Working Paper Series, 25406.

Burgess, S., E. Fernandez-Corugedo, C. Groth, R. Harrison, F. Monti, K. Theodoridis, M. Waldron, S. Burgess, E. Fernandez-Corugedo, C. Groth, R. Harrison, F. Monti, K. Theodoridis, and M. Waldron (2013): "The Bank of England 's Forecasting Platform: COMPASS, MAPS , EASE and the Suite of Models," Bank of England Working Paper Series, 471.

Calvo, G. A. (1983): "Staggered Prices in a Utility Maximizing Framework," Journal of Monetary Economics, 12, 383-398.

Carroll, C. D. (2006): "The Method of Endogeneous Gridpoints for Solving Dynamic Stochastic Optimization Problems," Economics Letters, 91, 312-320.

Christiano, L. J., R. Motto, and M. Rostagno (2010): "Financial Factors in Economic Fluctuations," ECB Working Paper Series, 1192.

(2014): "Risk Shocks," American Economic Review, 104, 27-65.

Christiano, L. J., M. Trabandt, And K. Walentin (2011): "Introducing Financial Frictions and Unemployment into a Small Open Economy Model," Journal of Economic Dynamics and Control, 35, 1999-2041. 
Coenen, G., P. Karadi, S. Schmidt, And A. Warne (2018): "The New Area-Wide Model II: An Extended Version of the ECB's Micro-Founded Model for Forecasting and Policy Analysis with a Financial Sector," ECB Working Paper Series, 2200.

Coibion, O. And Y. Gorodnichenko (2012): "Why Are Target Interest Rate Changes so Persistent?" American Economic Journal: Macroeconomics, 4, 126-162.

Coibion, O., Y. Gorodnichenko, and J. Wieland (2012): "The Optimal Inflation Rate in New Keynesian Models: Should Central Banks Raise Their Inflation Targets in Light of the Zero Lower Bound?" Review of Economic Studies, 79, 1371-1406.

Darracq Pariès, M., C. K. Sørensen, and D. Rodriguez-Palenzuela (2011): "Macroeconomic Propagation under Different Regulatory Regimes: Evidence from an Estimated DSGE Model for the Euro Area," International Journal of Central Banking, $7,49-112$.

De Fiore, F. And O. Tristani (2013): "Optimal Monetary Policy in a Model of the Credit Channel," Economic Journal, 123, 906-931.

De Paoli, B. And M. Paustian (2017): "Coordinating Monetary and Macroprudential Policies," Journal of Money, Credit and Banking, 49, 319-349.

Del Negro, M., M. Giannoni, and C. Patterson (2012): "The Forward Guidance Puzzle," Federal Reserve Bank of New York Staff Reports, 574.

Demiralp, S., J. Eisenschmidt, And T. Vlassopoulos (2019): "Negative Interest Rates, Excess Liquidity and Bank Business Models: Banks' Reaction to Unconventional Monetary Policy in the Euro Area," ECB Working Paper Series, 2283.

Eggertsson, G. B., R. E. Juelsrud, L. H. Summers, and E. Getz Wold (2019): "Negative Nominal Interest Rates and the Bank Lending Channel," NBER Working Paper Series, 25416.

Eisenschmidt, J. And F. Smets (2018): "Negative Interest Rates: Lessons from the Euro Area," Unpublished Manuscript.

Gertler, M. And P. Karadi (2011): "A Model of Unconventional Monetary Policy," Journal of Monetary Economics, 58, 17-34.

Guerrieri, L. And M. Iacoviello (2015): "OccBin: A Toolkit for Solving Dynamic Models with Occasionally Binding Constraints easily," Journal of Monetary Economics, $70,22-38$.

Güntner, J. H. (2015): "The Federal Funds Market, Excess Reserves, and Unconventional Monetary Policy," Journal of Economic Dynamics and Control, 53, 225-250.

Heider, F., F. Saidi, And G. Schepens (2019): "Life Below Zero: Bank Lending Under Negative Policy Rates," Review of Financial Studies (forthcoming). 
Jobst, A. And H. Lin (2016): "Negative Interest Rate Policy (NIRP): Implications for Monetary Transmission and Bank Profitability in the Euro Area," IMF Working Paper Series, $16 / 172$.

Lemke, W. And A. L. Vladu (2017): "Below the Zero Lower Bound: A Shadow-Rate Term Structure Model," ECB Working Paper Series, 1991.

Melosi, L. (2017): "Signalling Effects of Monetary Policy," The Review of Economic Studies, 84, 853-884.

Nakata, T. And S. Schmidt (2019): "Gradualism and Liquidity Traps," Review of Economic Dynamics, 31, 182-199.

Porcellacchia, D. (2019): "Maturity Transformation and Negative Interest Rate Policies," Unpublished Manuscript.

Primiceri, G. E., E. Schaumburg, and A. Tambalotti (2006): "Intertemporal Disturbances," NBER Working Paper Series, 12243.

Rognlie, M. (2016): "What Lower Bound? Monetary Policy with Negative Interest Rates," Unpublished Manuscript.

Rudebusch, G. D. (2002): "Term Structure Evidence on Interest Rate Smoothing and Monetary Policy Inertia," Journal of Monetary Economics, 49, 1161-1187.

- (2006): "Monetary Policy Inertia: Fact or Fiction?" International Journal of Central Banking, 2, 85-135.

Rudolf, B. And M. Zurlinden (2014): "A Compact Open Economy DSGE Model for Switzerland," SNB Economic Studies, 8.

Smets, F. And R. Wouters (2003): "An Estimated Dynamic Stochastic General Equilibrium Model of the Euro Area," Journal of the European Economic Association, 1, $1123-1175$.

(2007): "Shocks and Frictions In US Business Cycles: A Bayesian DSGE Approach," American Economic Review, 97, 586-606.

Sugo, T. And K. Ueda (2007): "Estimating a DSGE Model for Japan: Evaluating and Modifying a CEE/SW/LOWW Model," Bank of Japan Working Paper, 07-E.

Tauchen, G. And R. Hussey (1991): "Quadrature-Based Methods for Obtaining Approximate Solutions to Nonlinear Asset Pricing Models," Econometrica, 59, 371-396.

Woodford, M. (2003): "Optimal Interest-Rate Smoothing," Review of Economic Studies, 70, 861-886.

Wu, J. C. AND F. D. Xia (2018): "Negative Interest Rate Policy and the Yield Curve," NBER Working Paper Series, 25180. 


\section{A The model: Derivations}

\section{A.1 Derivation of the financial sector equilibrium [Section 2.2]}

A banker $i$ solves

$$
\nu_{f, t}=\max _{\left\{s_{i, t}, a_{i, t}, d_{i, t}, n_{i, t}\right\}} \mathbb{E}_{t} m_{t, t+1}\left((1-\theta) n_{i, t+1}+\theta \nu_{f, t+1}\right)
$$

subject to

$$
\begin{aligned}
q_{i, t} s_{i, t}+a_{i, t} & =d_{i, t}+n_{i, t}, \\
\nu_{f, i, t} & \geq \lambda q_{i, t} s_{i, t}, \\
a_{i, t} & =\alpha d_{i, t}, \\
n_{i, t+1} & =r_{k, t+1} q_{t} s_{i, t}+\frac{r_{t}}{\pi_{t+1}} a_{i, t}-\frac{r_{d, t}}{\pi_{t+1}} d_{i, t},
\end{aligned}
$$

where the constraints are the balance sheet constraint, incentive compatibility constraint, reserve ratio, and net worth accumulation, respectively. We calibrate the model such that the incentive constraint is always binding. Next, we simplify the system of constraints by substituting reserves, $a_{i, t}$, and deposits, $d_{i, t}$, making use of Equations (A.2) and (A.4). We also define $\phi_{t} \equiv q_{t} s_{i, t} / n_{i, t}$ to be the leverage ratio of a banker (and $\phi_{t}$ is common across banks). Thus, the accumulation of net worth, (A.5), is given by

$$
n_{i, t+1}=\left(r_{k, t+1} \phi_{t}-\frac{r_{d, t}-\alpha r_{t}}{(1-\alpha) \pi_{t+1}}\left(\phi_{t}-1\right)\right) n_{i, t}
$$

Furthermore, we conjecture the value function to take the form

$$
\nu_{f, t}=\left(\zeta_{s, t} \phi_{t}+\zeta_{n, t}\right) n_{i, t}
$$

where $\zeta_{s, t}$ and $\zeta_{n, t}$ are as yet undetermined.

Substituting (A.6) and (A.7), the banker's problem can be rewritten as

$$
\begin{aligned}
\left(\zeta_{s, t} \phi_{t}+\zeta_{n, t}\right)=\max _{\phi_{t}} \mathbb{E}_{t} m_{t, t+1}((1-\theta) & \left.+\theta\left(\zeta_{s, t+1} \phi_{t+1}+\zeta_{n, t+1}\right)\right) \\
\times & \left(r_{k, t+1} \phi_{t}-\frac{r_{d, t}-\alpha r_{t}}{(1-\alpha) \pi_{t+1}}\left(\phi_{t}-1\right)\right),
\end{aligned}
$$

subject to

$$
\zeta_{s, t} \phi_{t}+\zeta_{n, t}=\lambda \phi_{t}
$$


We rearrange the incentive compatibility constraint (A.9) and iterate one period forward to find optimal (and maximum) leverage given by

$$
\phi_{t+1}=\frac{\zeta_{n, t+1}}{\lambda-\zeta_{s, t+1}}
$$

With (A.10), comparing the left and right hand side of (A.8), we verify the conjectured functional form of the value function. This allows us to summarize the solution to the financial intermediary's problem in the binding incentive constraint given by

$$
\lambda \phi_{t}=\mathbb{E}_{t} m_{t, t+1}\left((1-\theta)+\theta \lambda \phi_{t+1}\right)\left(r_{k, t+1} \phi_{t}-\frac{r_{d, t}-\alpha r_{t}}{(1-\alpha) \pi_{t+1}}\left(\phi_{t}-1\right)\right) .
$$

Aggregate net worth in the financial sector evolves as a weighted sum of existing banks' accumulated net worth (A.6) and start up funds new banks receive from the household. Entering banks receive a fraction $\omega$ of the total value of intermediated assets, i.e. $\omega q_{t} s_{t-1}$. In equilibrium, $s_{t}=k_{t}$. Thus, the evolution of aggregate net worth is given by

$$
n_{t}=\theta\left(r_{k, t} \phi_{t-1}-\frac{r_{d, t-1}-\alpha r_{t-1}}{(1-\alpha) \pi_{t}}\left(\phi_{t-1}-1\right)\right) n_{t-1}+\omega q_{t} k_{t-1} .
$$

Equations (A.11) and (A.12) express the financial sector problem in just two equations. This completes the derivation. 


\section{A.2 List of equilibrium conditions [Section 2.5]}

In equilibrium, the model is summarized by 22 equations in 22 endogeneous variables, $\left\{y_{t}, l_{t}, c_{t}, \tilde{c}_{t}, m_{t, t+1}, \mu_{t}, k_{t}, i_{t}, i_{n, t}, n_{t}, \phi_{t}, w_{t}, \pi_{t}, x_{t}, p_{m, t}, p_{*, t}, p_{t}, q_{t}, r_{k, t}, r_{T, t}, r_{t}, r_{d, t}\right\}$, and 3 exogenous processes, $\left\{\beta_{t}, \varepsilon_{z, t}, \varepsilon_{m, t}\right\}$. Government expenditure, $g_{t}$, is financed via lump-sum taxes and kept constant.

\section{Households}

- Euler equation

$$
1=\mathbb{E}_{t} m_{t, t+1} r_{d, t} / \pi_{t+1}
$$

- Labor supply

$$
\mu_{t} w_{t}=\chi l_{t}^{\varphi}
$$

- Stochastic discount factor

$$
m_{t, t+1}=\beta_{t} \mu_{t+1} / \mu_{t}
$$

- Marginal utility of consumption

$$
\mu_{t}=\tilde{c}_{t}^{-\sigma}-\beta_{t} \hbar \mathbb{E}_{t} \tilde{c}_{t+1}^{-\sigma}
$$

\section{Financial intermediaries}

- Incentive compatibility constraint

$$
\lambda \phi_{t}=\mathbb{E}_{t} m_{t, t+1}\left((1-\theta)+\theta \lambda \phi_{t+1}\right)\left(r_{k, t+1} \phi_{t}-\frac{r_{d, t}-\alpha r_{t}}{(1-\alpha) \pi_{t+1}}\left(\phi_{t}-1\right)\right)
$$

- Evolution of aggregate net worth

$$
n_{t}=\theta\left(r_{k, t} \phi_{t-1}-\frac{r_{d, t-1}-\alpha r_{t-1}}{(1-\alpha) \pi_{t}}\left(\phi_{t-1}-1\right)\right) n_{t-1}+\omega q_{t} k_{t-1}
$$

\section{Producers}

- Price of capital

$$
\begin{aligned}
1 & =q_{t}\left(1-\frac{\eta_{I}}{2}\left(\frac{i_{n, t}+i_{s s}}{i_{n, t-1}+i_{s s}}-1\right)^{2}-\eta_{I}\left(\frac{i_{n, t}+i_{s s}}{i_{n, t-1}+i_{s s}}-1\right) \frac{i_{n, t}}{i_{n, t-1}+i_{s s}}\right) \\
& +\mathbb{E}_{t} m_{t, t+1} q_{t+1}\left(\eta_{I}\left(\frac{i_{n, t+1}+i_{s s}}{i_{n, t}+i_{s s}}-1\right) \frac{i_{n, t+1}+i_{s s}}{\left(i_{n, t}+i_{s s}\right)^{2}} i_{n, t+1}\right)
\end{aligned}
$$


- Production function

$$
y_{t}=\exp \left(\varepsilon_{z, t}\right) k_{t-1}^{\gamma} l_{t}^{1-\gamma}
$$

- Labor demand

$$
w_{t}=p_{m, t}\left((1-\gamma) y_{t} / l_{t}\right)
$$

- Return on capital

$$
r_{k, t}=\frac{p_{m, t}\left(\gamma y_{t} / k_{t-1}\right)+q_{t}-\delta}{q_{t-1}}
$$

- Reset price

$$
\mathbb{E}_{t} \sum_{\tau=0}^{\infty} \iota^{\tau} m_{t, t+\tau}\left(\frac{p_{*, t}}{p_{t+\tau}} \prod_{k=1}^{\tau} \pi_{t+k-1}^{\gamma_{p}}-\frac{\epsilon}{\epsilon-1} p_{m, t+\tau}\right) y_{i, t+\tau}=0 .
$$

- Price index

$$
p_{t}=\left((1-\iota) p_{*, t}^{1-\epsilon}+\iota p_{t-1}^{1-\epsilon}\right)^{1 /(1-\epsilon)}
$$

\section{Monetary policy}

- Policy rule

$$
r_{T, t}=\left(r_{s s}\left(\frac{\pi_{t}}{\pi_{s s}}\right)^{\phi_{\pi}}\left(\frac{x_{t}}{x_{s s}}\right)^{\phi_{x}}\right)^{1-\rho} r_{t-1}^{\rho} \exp \left(\varepsilon_{m, t}\right)
$$

- No arbitrage

$$
\begin{aligned}
\text { (I) } & r_{t}=r_{d, t}=r_{T, t}, \text { or } \\
\text { (II) } & r_{t}=r_{d, t}=\max \left\{1, r_{T, t}\right\} \text {, or } \\
\text { (III) } & r_{t}=r_{T, t} \text { and } r_{d, t}=\max \left\{1, r_{T, t}\right\} .
\end{aligned}
$$

\section{General equilibrium}

- Aggregate resource constraint

$$
y_{t}=c_{t}+i_{t}+g_{t}
$$

- Capital accumulation

$$
k_{t}=k_{t-1}+f\left(i_{n, t}, i_{n, t-1}\right)
$$

where

$$
k_{n, t}=f\left(i_{n, t}, i_{n . t-1}\right) \equiv\left(1-\left(\eta_{i} / 2\right)\left(\left(i_{n, t}+i_{s s}\right) /\left(i_{n, t-1}+i_{s s}\right)-1\right)^{2}\right) i_{n, t} .
$$




\section{Definitions}

- Habit adjusted consumption

$$
\tilde{c}_{t}=c_{t}-\hbar c_{t-1}
$$

- Total investment

$$
i_{t}=i_{n, t}+\delta k_{t-1}
$$

- Inflation

$$
\pi_{t}=p_{t} / p_{t-1}
$$

- Leverage

$$
\phi_{t}=q_{t} k_{t} / n_{t}
$$

- Marginal cost

$$
x_{t}=p_{m, t}
$$




\section{B Optimal policy: Derivations \& computation}

In this section we provide detailed derivations for the stylized new-Keynesian model we use in Section 4. We derive the first-order conditions under both commitment and discretion; prove Propositions 1 and 2; document the non-linear solution algorithm used for the numerical example; derive the consumption equivalent measure of welfare and provide additional welfare results; and derive analytical results for the simplified version of the model that effectively reduces to a two-period problem. ${ }^{22}$

\section{B.1 Proposition 1 [Section 4.1]}

Under full commitment, the recursive problem of the optimal policymaker is given by

$$
\begin{aligned}
V & =\max _{\left\{\pi, y, r, r_{d}\right\}}-\frac{1}{2}\left(\pi^{2}+\lambda y^{2}\right)+\beta \mathbb{E}_{g^{\prime} \mid g} V^{\prime} \\
\pi & =\beta \mathbb{E}_{g^{\prime} \mid g} \pi^{\prime}+\kappa y \\
y & =\mathbb{E}_{g^{\prime} \mid g} y^{\prime}-\sigma^{-1}\left(r_{d}-\mathbb{E}_{g^{\prime} \mid g} \pi^{\prime}-g\right)-\phi\left(r_{d}-r\right), \\
r_{d} & \geq 0 \quad(\mathrm{ZLB}), \quad r_{d}-r \geq 0 \quad(\mathrm{ARB}), \quad r_{d}\left(r_{d}-r\right)=0 \quad(\mathrm{X}) .
\end{aligned}
$$

The first-order conditions are given by

$$
\begin{aligned}
\pi: & 0 & =\pi-\zeta_{P C}^{\prime}+\zeta_{P C}+\sigma^{-1} \beta^{-1} \zeta_{I S}, \\
y: & 0 & =\lambda y+\kappa \zeta_{P C}^{\prime}-\zeta_{I S}^{\prime}+\beta^{-1} \zeta_{I S}, \\
r_{d}: & 0 & =\zeta_{I S}^{\prime}\left(\sigma^{-1}+\phi\right)+\zeta_{Z L B}+\zeta_{A R B}+\zeta_{X}\left(2 r_{d}-r\right), \\
r: & 0 & =\zeta_{I S}^{\prime} \phi+\zeta_{A R B}+\zeta_{X} r_{d}, \\
K T_{1}: & 0 & =\zeta_{Z L B} r_{d}, \\
K T_{2}: & 0 & =\zeta_{A R B}\left(r_{d}-r\right),
\end{aligned}
$$

where the $\zeta$ variables are Lagrange multipliers. The equilibrium for $\left\{\pi, y, r_{d}, r, \zeta_{I S}, \zeta_{P C}\right\}$ can be simplified to the following set of six conditions:

$$
\begin{aligned}
\pi & =\beta \mathbb{E}_{g^{\prime} \mid g} \boldsymbol{\pi}\left(\zeta_{P C}^{\prime}, \zeta_{I S}^{\prime}, g^{\prime}\right)+\kappa y, \\
y & =\mathbb{E}_{g^{\prime} \mid g} \boldsymbol{y}\left(\zeta_{P C}^{\prime}, \zeta_{I S}^{\prime}, g^{\prime}\right)-\sigma^{-1}\left(r_{d}-\mathbb{E}_{g^{\prime} \mid g} \boldsymbol{\pi}\left(\zeta_{P C}^{\prime}, \zeta_{I S}^{\prime}, g^{\prime}\right)-g\right)-\phi\left(r_{d}-r\right), \\
0 & =\pi-\zeta_{P C}^{\prime}+\zeta_{P C}+\sigma^{-1} \beta^{-1} \zeta_{I S}, \\
0 & =\lambda y+\kappa \zeta_{P C}^{\prime}-\zeta_{I S}^{\prime}+\beta^{-1} \zeta_{I S},
\end{aligned}
$$

\footnotetext{
${ }^{22}$ Note that in the interest of expositional clarity, we simplify the notation compared to Section 4 . In particular, we drop time subscripts and replace them with recursive notation. $y$ denotes the output gap.
} 
with the final two equilibrium conditions written in terms of three regimes as follows:

$$
\begin{array}{rlr}
\text { Regime I }(r>0): & 0=\zeta_{I S}^{\prime}, & r_{d}=r, \\
\text { Regime II }(r<0): & 0=\zeta_{I S}^{\prime} \phi r, & r_{d}=0, \\
\text { Regime III }(r=0): & 0=r, & r_{d}=0 .
\end{array}
$$

Proof of Proposition 1. Proposition 1 states that, under commitment, the reserve rate will never be set negative. This is equivalent to stating, $r \in$ Regime II is not optimal. We prove this by contradiction.

For a given state vector, $\boldsymbol{s}=\left\{\zeta_{I S}, \zeta_{P C}, g\right\}$, define $r^{\mathrm{c}, \mathrm{zlb}}(\boldsymbol{s})$ and $r_{d}^{\mathrm{c}, \mathrm{zlb}}(\boldsymbol{s})$ as the reserve and deposit rate, respectively, that are the solution to the constrained commitment problem where negative reserve rates are not an option, i.e. $r \in\{$ Regime I, Regime III $\}$, and $r^{c, n i r}(s)$ and $r_{d}^{c, n i r}(s)$ as the reserve and deposit rate that solve the commitment problem where negative reserve rates are allowed, i.e. $r \in\{$ Regime I, Regime II, Regime III $\}$.

Consider $\phi>0$ :

Suppose $\exists \boldsymbol{s} \mid V^{\mathrm{c}, \text { nir }}(\boldsymbol{s})>V^{\mathrm{c}, \mathrm{zlb}}(\boldsymbol{s}) \longrightarrow r^{\mathrm{c}, \text { nir }}<0$ and $r_{d}^{\mathrm{c}, \text { nir }}=0$ (Regime II). Then, (B.2) reduces to $y=\mathbb{E}_{g^{\prime} \mid g} \boldsymbol{y}\left(\boldsymbol{s}^{\prime}\right)+\sigma^{-1}\left(\mathbb{E}_{g^{\prime} \mid g} \boldsymbol{\pi}\left(\boldsymbol{s}^{\prime}\right)+g\right)+\phi r^{\mathrm{c}, \text { nir }}$. Yet, $r^{\mathrm{c},{ }^{*}}=r_{d}^{\mathrm{c},{ }^{*}}=-\phi \sigma r^{\mathrm{c}, \text { nir }}>0$ and $\zeta_{I S}^{\prime}=0$ (Regime I) generates the same equilibrium outcome, $V^{\mathrm{c},{ }^{*}}(\boldsymbol{s})=V^{\mathrm{c}, \text { nir }}(\boldsymbol{s})$. However, $r^{\mathrm{c},{ }^{*}}$ and $r_{d}^{\mathrm{c}, *}$ are in the space of the constrained commitment problem such that $V^{\mathrm{c},{ }^{*}}(\boldsymbol{s})=V^{\mathrm{c}, \text { nir }}(\boldsymbol{s}) \leq V^{\mathrm{c}, \mathrm{zlb}}(\boldsymbol{s})$. Thus, we have a contradiction.

Consider $\phi=0$ :

The reserve rate drops out of the equilibrium system that determines $\left\{y, \pi, r_{d}, \zeta_{I S}, \zeta_{P C}\right\}$ as $\phi\left(r_{d}-r\right)=0 \forall r$ in (B.2). There is no role for negative interest rates. 


\section{B.2 Proposition 2 [Section 4.1]}

To study optimal time-consistent policy with and without policy smoothing, we augment the policymaker's objective function by adding a preference for smoothing interest rates, given by $\psi$. Under discretion, the recursive planner's problem is then given by

$$
\begin{aligned}
\boldsymbol{V}(r, g) & =\max _{\left\{\pi, y, r^{\prime}, r_{d}\right\}}-\frac{1}{2}\left((1-\psi)\left(\pi^{2}+\lambda y^{2}\right)-\psi\left(r^{\prime}-r\right)^{2}\right)+\beta \mathbb{E}_{g^{\prime} \mid g} \boldsymbol{V}\left(r^{\prime}, g^{\prime}\right) \\
\pi & =\beta \mathbb{E}_{g^{\prime} \mid g} \boldsymbol{\pi}\left(r^{\prime}, g^{\prime}\right)+\kappa y, \\
y & =\mathbb{E}_{g^{\prime} \mid g} \boldsymbol{y}\left(r^{\prime}, g^{\prime}\right)-\sigma^{-1}\left(r_{d}-\mathbb{E}_{g^{\prime} \mid g} \boldsymbol{\pi}\left(r^{\prime}, g^{\prime}\right)-g\right)-\phi\left(r_{d}-r^{\prime}\right), \\
r_{d} & \geq 0 \quad(\mathrm{ZLB}), \quad r_{d}-r^{\prime} \geq 0 \quad(\mathrm{ARB}), \quad r_{d}\left(r_{d}-r^{\prime}\right)=0 \quad(\mathrm{X}) .
\end{aligned}
$$

The first-order conditions and the envelope condition are given by

$$
\begin{array}{rlrl}
\pi: & & (1-\psi) \pi & =\zeta_{P C}, \\
y: & (1-\psi) \lambda y & =\zeta_{I S}-\kappa \zeta_{P C}, \\
r_{d}: & 0 & =\zeta_{I S}\left(\sigma^{-1}+\phi\right)+\zeta_{Z L B}+\zeta_{A R B}+\zeta_{X}\left(2 r_{d}-r^{\prime}\right), \\
r^{\prime}: & 0 & =\psi\left(r^{\prime}-r\right)-\beta \mathbb{E}_{g^{\prime} \mid g} \boldsymbol{V}_{1}\left(r^{\prime}, g^{\prime}\right)+\beta \mathbb{E}_{g^{\prime} \mid g} \boldsymbol{\pi}_{1}\left(r^{\prime}, g^{\prime}\right) \zeta_{P C} \\
& +\zeta_{I S}\left(\mathbb{E}_{g^{\prime} \mid g} \boldsymbol{y}_{1}\left(r^{\prime}, g^{\prime}\right)+\sigma^{-1} \mathbb{E}_{g^{\prime} \mid g} \boldsymbol{\pi}_{1}\left(r^{\prime}, g^{\prime}\right)+\phi\right)+\zeta_{A R B}+\zeta_{X} r_{d}, \\
\mathrm{KT}_{1}: & 0 & =\zeta_{Z L B} r_{d}, \\
\mathrm{KT}_{2}: & 0 & =\zeta_{A R B}\left(r_{d}-r^{\prime}\right), \\
\mathrm{EC}: & \boldsymbol{V}_{1}(r, g) & =\psi\left(r^{\prime}-r\right) .
\end{array}
$$

where the $\zeta$ variables are Lagrange multipliers. Again, making use of the three regimes, the equilibrium for $\left\{\pi, y, r_{d}, r^{\prime}, \zeta_{I S}, \zeta_{P C}\right\}$, can be simplified to a set of four conditions:

$$
\begin{aligned}
& \pi=\beta \mathbb{E}_{g^{\prime} \mid g} \boldsymbol{\pi}\left(r^{\prime}, g^{\prime}\right)+\kappa y, \\
& y=\mathbb{E}_{g^{\prime} \mid g} \boldsymbol{y}\left(r^{\prime}, g^{\prime}\right)-\sigma^{-1}\left(r_{d}-\mathbb{E}_{g^{\prime} \mid g} \boldsymbol{\pi}\left(r^{\prime}, g^{\prime}\right)-g\right)-\phi\left(r_{d}-r^{\prime}\right),
\end{aligned}
$$$$
\text { Regime I: }\left(r^{\prime}>0\right)
$$$$
0=\psi(1+\beta) r^{\prime}-\psi r-\psi \beta \mathbb{E}_{g^{\prime} \mid g} \boldsymbol{r}\left(r^{\prime}, g^{\prime}\right)+(1-\psi) \beta \mathbb{E}_{g^{\prime} \mid g} \boldsymbol{\pi}_{1}\left(r^{\prime}, g^{\prime}\right) \pi
$$$$
+(1-\psi)\left(\mathbb{E}_{g^{\prime} \mid g} \boldsymbol{y}_{1}\left(r^{\prime}, g^{\prime}\right)+\sigma^{-1} \mathbb{E}_{g^{\prime} \mid g} \boldsymbol{\pi}_{1}\left(r^{\prime}, g^{\prime}\right)-\sigma^{-1}\right)(\lambda y+\kappa \pi), \quad r_{d}=r^{\prime} .
$$

Regime II : $\left(r^{\prime}<0\right)$

$$
\begin{aligned}
0 & =\psi(1+\beta) r^{\prime}-\psi r-\psi \beta \mathbb{E}_{g^{\prime} \mid g} \boldsymbol{r}\left(r^{\prime}, g^{\prime}\right)+(1-\psi) \beta \mathbb{E}_{g^{\prime} \mid g} \boldsymbol{\pi}_{1}\left(r^{\prime}, g^{\prime}\right) \pi \\
& +(1-\psi)\left(\mathbb{E}_{g^{\prime} \mid g} \boldsymbol{y}_{1}\left(r^{\prime}, g^{\prime}\right)+\sigma^{-1} \mathbb{E}_{g^{\prime} \mid g} \boldsymbol{\pi}_{1}\left(r^{\prime}, g^{\prime}\right)+\phi\right)(\lambda y+\kappa \pi), \quad r_{d}=0 .
\end{aligned}
$$

Regime III: $\left(r^{\prime}=0\right)$

$$
r^{\prime}=r_{d}=0
$$


Proof of Proposition 2. Proposition 2 states that, under discretion, with $\psi=0$, the reserve rate will never be set negative. Equivalently, $r \in$ Regime II is not optimal. We prove this by contradiction.

When $\psi=0$ the equilibrium system of equations reduces to

$$
\begin{aligned}
\pi & =\beta \mathbb{E}_{g^{\prime} \mid g} \boldsymbol{\pi}\left(g^{\prime}\right)+\kappa y, \\
y & =\mathbb{E}_{g^{\prime} \mid g} \boldsymbol{y}\left(g^{\prime}\right)-\sigma^{-1}\left(r_{d}-\mathbb{E}_{g^{\prime} \mid g} \boldsymbol{\pi}\left(g^{\prime}\right)-g\right)-\phi\left(r_{d}-r\right), \\
0 & =\lambda y+\kappa \pi, \\
\text { Regime I: } & r_{d}=r \quad \text { if } \quad r>0, \\
\text { Regime II: } & r_{d}=0 \text { if } \quad r<0, \\
\text { Regime III: } & r_{d}=0 \text { if } \quad r=0,
\end{aligned}
$$

where the reserve rate is no longer a state variable.

For a given state vector, $g$, define $r^{\mathrm{d}, \mathrm{zlb}}(g)$ and $r_{d}^{\mathrm{d}, \mathrm{zlb}}(g)$ as the reserve and deposit rate, respectively, that are the solution to the constrained problem under discretion where negative reserve rates are not an option, i.e. $r \in\{$ Regime I, Regime III $\}$, and $r^{\mathrm{d}, \text { nir }}(g)$ and $r_{d}^{\mathrm{d}, \mathrm{nir}}(g)$ as the reserve and deposit rate that solve the problem under discretion where negative reserve rates are allowed, i.e. $r \in\{$ Regime I, Regime II, Regime III $\}$.

Consider $\phi>0$ :

Suppose $\exists g \mid V^{\mathrm{d} \text {,nir }}(g)>V^{\mathrm{d}, \mathrm{zlb}}(g) \longrightarrow r^{\mathrm{d} \text {,nir }}<0$ and $r_{d}^{\mathrm{d}, \text { nir }}=0$ (Regime II). Then, (B.6) reduces to $y=\mathbb{E}_{g^{\prime} \mid g} \boldsymbol{y}\left(g^{\prime}\right)+\sigma^{-1}\left(\mathbb{E}_{g^{\prime} \mid g} \boldsymbol{\pi}\left(g^{\prime}\right)+g\right)+\phi r^{\mathrm{d}, \text { nir }}$. Yet, $r^{\mathrm{d},{ }^{*}}=r_{d}^{\mathrm{d}, *}=-\phi \sigma r^{\mathrm{d}, \text { nir }}>0$ (Regime I) generates the exact same equilibrium outcome, yielding $V^{\mathrm{d},{ }^{*}}(g)=V^{\mathrm{d}, \text { nir }}(g)$. However, $r^{\mathrm{d},{ }^{*}}$ and $r_{d}^{\mathrm{d},{ }^{*}}$ are in the space of the constrained problem under discretion such that $V^{\mathrm{d},{ }^{*}}(g)=V^{\mathrm{d}, \text { nir }}(g) \leq V^{\mathrm{d}, \mathrm{zlb}}(g)$. Thus, we have a contradiction.

Consider $\phi=0$ :

The reserve rate drops out of the equilibrium system that determines $\left\{y, \pi, r_{d}\right\}$ since $\phi\left(r_{d}-r\right)=0 \forall r$ in (B.6). There is no role for negative interest rates. 


\section{B.3 Policy function iteration [Section 4.2]}

To derive a solution to the time-consistent optimal policymaker's problem, we use a policy function iteration algorithm, solving for $\pi(r, g), y(r, g), r^{\prime}(r, g), r_{d}(r, g), \zeta_{Z L B}(r, g)$, and $\zeta_{A R B}(r, g)$. The algorithm proceeds as follows:

1. Set $N_{i}$ : number of points on the interest rate grid, $N_{s}$ : number of exogenous states, $\epsilon$ : tolerance limit for convergence, $\mathrm{u}$ : updating parameter. Set grid points $\left\{i_{0}, \ldots, i_{N_{i}}\right\}$. The $\operatorname{AR}(1)$ process for the natural rate, $g$, is approximated using Tauchen and Hussey (1991)'s quadrature algorithm that gives a set of grid points $\left\{s_{0}, \ldots, s_{N_{s}}\right\}$ and a transmission matrix, $M$.

2. Start iteration $j$ with conjectured functions for $r^{\prime j}(r, g)$ and $\pi^{j}(r, g)$. The initial functions are set to $r^{\prime 0}(r, g)=1 / \beta-1$ and $\pi^{0}(r, g)=0 . \pi(r, g)$ is only defined at the nodes of the grids for the policy rate and shock, but since $r^{\prime}(r, g)$ is generally not going to match node grids exactly, the function $\pi(r, g)$ is interpolated over the first argument to determine its values at $\boldsymbol{\pi}^{j}\left(r^{\prime j}(r, g), g^{\prime}\right)$. Construct expectations $\mathbb{E} \boldsymbol{\pi}^{j}\left(r^{\prime j}(r, g), g^{\prime}\right)$, denoted $\mathbb{E} \boldsymbol{\pi}^{j}$ for short. Repeat for $r^{\prime}$, giving $\mathbb{E} \boldsymbol{r}^{j}$.

3. Using the Phillips curve, calculate $y$ :

$$
y^{j}(r, g)=\frac{1}{\kappa}\left(\pi^{j}(r, g)-\mathbb{E}^{j} \boldsymbol{\pi}\right) .
$$

4. Construct one-step ahead output gap expectations, $\mathbb{E} \boldsymbol{y}^{j}$.

5. Construct the deposit rate function $r_{d}(r, g)=\max \left(0, r^{\prime j}(r, g)\right)$.

6. Using the IS and Phillips curve, re-calculate $y$ and $\pi$, respectively:

$$
\begin{aligned}
& y^{*}(r, g)=\mathbb{E} \boldsymbol{y}^{j}-\sigma^{-1}\left(r_{d}(r, g)-\mathbb{E} \boldsymbol{\pi}^{j}-g\right)-\phi\left(r_{d}(r, g)-r^{j}(r, g)\right), \\
& \pi^{*}(r, g)=\beta \mathbb{E} \boldsymbol{\pi}^{j}+\kappa y^{*}(r, g),
\end{aligned}
$$

and then update expectations, $\mathbb{E} \boldsymbol{y}^{*}$ and $\mathbb{E} \boldsymbol{\pi}^{*}$.

7. Construct numerical derivatives of $\pi$ as follows:

$$
\pi_{1}(r, g) \equiv \frac{\partial \pi^{*}(r, g)}{\partial r}=\left\{\begin{array}{ccc}
\frac{\pi^{*}\left(i_{k}, g\right)-\pi^{*}\left(i_{k-1}, g\right)}{i_{k}-i_{k-1}} & \text { for } & k=1, \ldots, N_{i} \\
\frac{\pi^{*}\left(i_{1}, g\right)-\pi^{*}\left(i_{0}, g\right)}{i_{1}-i_{0}} & \text { for } & k=0 .
\end{array}\right.
$$

and denote the function $\pi_{1}$ for short. Calculate the one-step ahead values of these derivative functions, $\boldsymbol{\pi}_{1}\left(r^{\prime j}(r, g), g^{\prime}\right)$, and calculate expectations, denoted $\mathbb{E} \boldsymbol{\pi}_{1}$. Repeat for $y$ giving $\mathbb{E} \boldsymbol{y}_{1}$. 
8. Using the FOC equation to re-calculate $r^{\prime}$ :

$$
\begin{aligned}
& \text { for } \quad r^{\prime j}(r, g)>0, \\
& \qquad r^{\prime *}(r, g)=\frac{1}{\psi(1+\beta)}\left(\begin{array}{c}
\psi r+\psi \beta \mathbb{E} \boldsymbol{r}^{j}-(1-\psi) \beta \mathbb{E} \boldsymbol{\pi}_{1} \pi^{*}(r, g)+\zeta_{Z L B}^{*}(r, g) \\
-(1-\psi)\left(\mathbb{E} \boldsymbol{y}_{1}+\sigma^{-1} \mathbb{E} \boldsymbol{\pi}_{1}-\sigma^{-1}\right)\left(\lambda y^{*}(r, g)+\kappa \pi^{*}(r, g)\right)
\end{array}\right),
\end{aligned}
$$

else

$$
r^{\prime *}(r, g)=\frac{1}{\psi(1+\beta)}\left(\begin{array}{c}
\psi r+\psi \beta \mathbb{E} \boldsymbol{r}^{j}-(1-\psi) \beta \mathbb{E} \boldsymbol{\pi}_{1} \pi^{*}(r, g)+\zeta_{Z L B}^{*}(r, g) \\
-(1-\psi)\left(\mathbb{E} \boldsymbol{y}_{1}+\sigma^{-1} \mathbb{E} \boldsymbol{\pi}_{1}+\phi\right)\left(\lambda y^{*}(r, g)+\kappa \pi^{*}(r, g)\right)
\end{array}\right),
$$

9. if $\max \left(\left(\pi^{*}(r, g)-\pi^{j}(r, g)\right),\left(r^{\prime} *(r, g)-r^{\prime j}(r, g)\right)\right)<\epsilon$, then stop.

else $j=j+1$ and update the guess as follows:

$$
\begin{aligned}
& \pi^{j}(r, g)=\mathrm{u} \pi^{j-1}(r, g)+(1-\mathrm{u}) \pi^{*}(r, g), \\
& r^{\prime j}(r, g)=\mathrm{u} r^{\prime j-1}(r, g)+(1-\mathrm{u}) r^{\prime *}(r, g) .
\end{aligned}
$$

Repeat steps 2-9. 


\section{B.4 Welfare [Section 4.2]}

The social welfare function can be translated into a consumption equivalent measure via

$$
C E=100 \times(1-\beta) \lambda^{-1}\left(\sigma^{-1}+\eta\right) \mathbb{E}\left(V^{S W}\right)
$$

where $\eta$ is the inverse labor supply elasticity, set to 0.47 in our calibration, and $\mathbb{E}\left(V^{S W}\right)$ is the unconditional mean of the social welfare function. $C E$ is the percentage of steady state consumption that the representative household would forgo in each period to avoid uncertainty. Less negative values thus represent an improvement in welfare. Figure B.1 plots the consumption equivalent measure of welfare across a range of values for the smoothing parameter, $\psi$. The figure demonstrates three features. One, allowing for negative interest rates in the toolkit of the policymaker is weakly welfare dominant. Two, it is optimal to delegate policy to a central banker with a small but meaningful preference for smoothing. Three, the optimal value of $\psi$ is virtually the same, irrespective of whether negative interest rates are available or not.

Figure B.1: Welfare and the optimal degree of smoothing

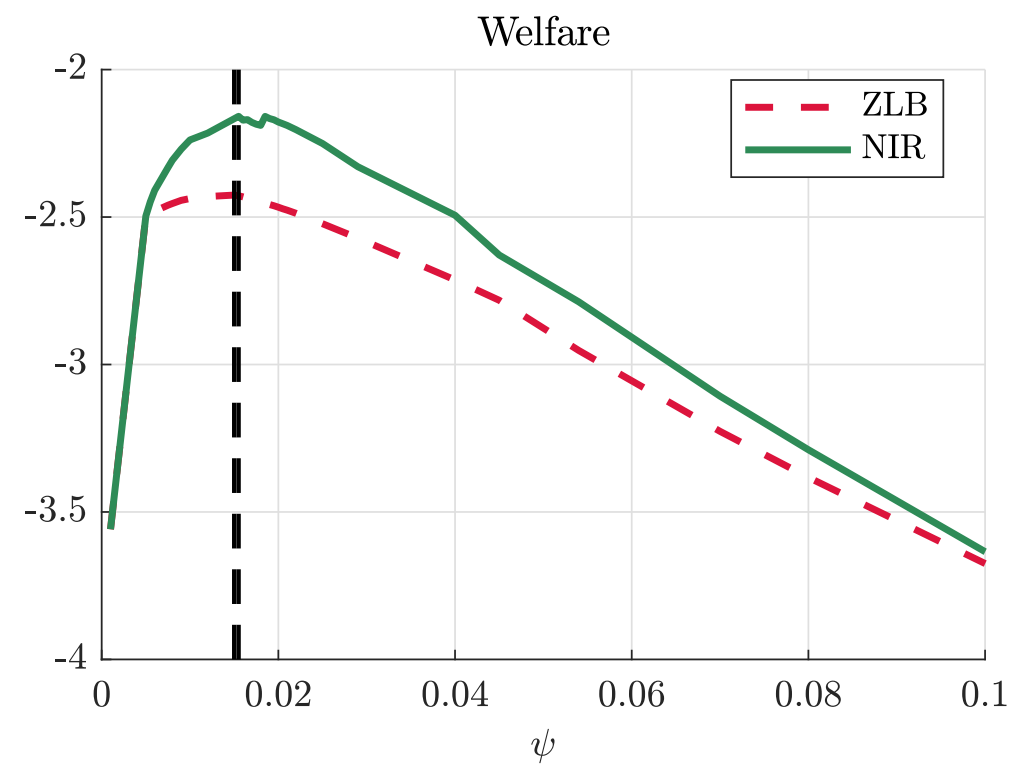

Note: Consumption equivalent as a percent of steady state consumption. Black-dash denotes the optimal value of $\psi$. ZLB denotes policy without negative interest rates. NIR denotes policy with negative rates. 


\section{B.5 Analytical derivations [Section 4.3]}

In Section 4.3 we set $\lambda=0$, we set $\psi=0$ except for between periods 1 and 2 , and we set $g_{t}=0$ for $t>1$. This allows for an analytical derivation of equilibrium outcomes. In particular, $\pi_{t}=y_{t}=0$ for $t>2$.

Thus, the central banks loss function reduces to

$$
-V \propto \pi_{1}^{2}+\beta\left((1-\psi) \pi_{2}^{2}+\psi\left(r_{2}-r_{1}\right)^{2}\right)
$$

The policymaker is subject to the following constraints

$$
\begin{aligned}
\pi_{1} & =\beta \pi_{2}+\kappa y_{1}, \\
y_{1} & =y_{2}-\sigma^{-1}\left(r_{d, 1}-\pi_{2}\right)-\phi\left(r_{d, 1}-r_{1}\right)+g, \\
\pi_{2} & =\kappa y_{2}, \\
y_{2} & =-\sigma^{-1} r_{2}, \\
r_{d, 1} & \geq-\bar{r} \\
r_{2} & \geq-\bar{r} \\
r_{d, 1}-r_{1} & \geq 0 \\
\left(r_{d, 1}+\bar{r}\right)\left(r_{d, 1}-r_{1}\right) & =0
\end{aligned}
$$

where the expectations operator has been dropped because there is no uncertainty. In addition, there is no incentive to set a negative interest rate in period 2 so $r_{d, 2}=r_{2}$. In contrast to the main text, we make $g$ mean zero and set the ZLB constraint as $-\bar{r}$.

We consider optimal policy under discretion. There are 4 possible equilibrium outcomes:

$$
\begin{array}{rll}
(++): & r_{1}>-\bar{r}, & r_{2}>-\bar{r} \\
(0+): & r_{1}=-\bar{r}, & r_{2}>-\bar{r} \\
(-+): & r_{1}<-\bar{r}, & r_{2}>-\bar{r} \\
(-0): & r_{1}=-\bar{r}, & r_{2}<-\bar{r}
\end{array}
$$

We solve the problem backwards. First soving for the optimal $r_{2}$ given a value for $r_{1}$.

For $(\cdot 0)$, we have

$$
r_{2}^{*(0)}=-\bar{r}
$$


For $(\cdot+)$, the period 2 problem is given by

$$
\min _{r_{2}}(1-\psi) \pi_{2}^{2}+\psi\left(r_{2}-r_{1}\right)^{2} \quad \text { s.t. } \quad \pi_{2}=-\kappa \sigma^{-1} r_{2} .
$$

The first-order condition is given by

$$
(1-\psi)\left(\kappa \sigma^{-1}\right)^{2} r_{2}+\psi\left(r_{2}-r_{1}\right)=0
$$

or, rearranged, as

$$
\begin{aligned}
r_{2}^{*(+)} & =R_{2}^{(+)} r_{1}, \\
\pi_{2}^{*(+)} & =\Pi_{2}^{(+)} r_{1}, \\
\text { where } \quad R_{2}^{(+)} & \equiv \frac{\psi}{\psi+(1-\psi)\left(\kappa \sigma^{-1}\right)^{2}}, \\
\Pi_{2}^{(+)} & \equiv-\kappa \sigma^{-1} R_{2}^{(+)} .
\end{aligned}
$$

Now that we have the optimal reaction function for $r_{2}$ as a function of $r_{1}$, we can solve the period 1 problem, taking the behaviour of the policymaker in period 2 as given.

For $(++)$, the period 1 problem is given by

$$
\begin{aligned}
& \min _{r_{1}} \quad \pi_{1}^{2}+\beta\left((1-\psi) \pi_{2}^{2}+\psi\left(r_{2}-r_{1}\right)^{2}\right) \\
& \text { s.t. } \quad \pi_{1}=\Pi_{1}^{(++)} r_{1}+\kappa g, \\
& \pi_{2}=\Pi_{2}^{(+)} r_{1}, \\
& r_{2}=R_{2}^{(+)} r_{1}, \\
& \text { where } \quad \Pi_{1}^{(++)} \equiv-\kappa\left(\left(\beta+1+\kappa \sigma^{-1}\right) \sigma^{-1} R_{2}^{(+)}+\sigma^{-1}\right),
\end{aligned}
$$

and the first-order condition is given by

$$
\left(\Pi_{1}^{(++)} r_{1}+\kappa g\right) \Pi_{1}^{(++)}+\beta\left((1-\psi)\left(\Pi_{2}^{(+)}\right)^{2} r_{1}+\psi\left(R_{2}^{(+)}-1\right)^{2} r_{1}\right)=0
$$

or, rearranged, as

$$
r_{1}^{*(++)}=-\frac{\kappa \Pi_{1}^{(++)} g}{\left(\Pi_{1}^{(++)}\right)^{2}+\beta\left((1-\psi)\left(\Pi_{2}^{(+)}\right)^{2}+\psi\left(R_{2}^{(+)}-1\right)^{2}\right)} .
$$


For $(-+)$, the constraints are given by

$$
\begin{aligned}
\pi_{1} & =\Pi_{1}^{(-+)} r_{1}+C \Pi_{1}^{(-+)} \bar{r}+\kappa g, \\
\pi_{2} & =\Pi_{2}^{(+)} r_{1}, \\
r_{2} & =R_{2}^{(+)} r_{1}, \\
\text { where } \quad \Pi_{1}^{(-+)} & \equiv-\kappa\left(\left(\beta+1+\kappa \sigma^{-1}\right) \sigma^{-1} R_{2}^{(+)}-\phi\right), \\
C \Pi_{1}^{(-+)} & \equiv \kappa\left(\sigma^{-1}+\phi\right),
\end{aligned}
$$

and the solution is given by

$$
r_{1}^{*(-+)}=-\frac{C \Pi_{1}^{(-+)} \Pi_{1}^{(-+)} \bar{r}+\kappa \Pi_{1}^{(-+)} g}{\left(\Pi_{1}^{(-+)}\right)^{2}+\beta\left((1-\psi)\left(\Pi_{2}^{(+)}\right)^{2}+\psi\left(R_{2}^{(+)}-1\right)^{2}\right)} .
$$

For $(0+)$, we have

$$
r_{1}^{*(0+)}=-\bar{r}
$$

For $(-0)$, the constraints are given by

$$
\begin{aligned}
\pi_{1} & =\Pi_{1}^{(-0)} r_{1}+C \Pi_{1}^{(-0)} \bar{r}+\kappa g, \\
\pi_{2} & =C \Pi_{2}^{(0)} \bar{r}, \\
r_{2} & =-\bar{r}, \\
\text { where } \quad \Pi_{1}^{(-0)} & \equiv \kappa \phi, \\
C \Pi_{1}^{(-0)} & \equiv \kappa\left(\left(\beta+2+\kappa \sigma^{-1}\right) \sigma^{-1}+\phi\right), \\
C \Pi_{2}^{(0)} & \equiv \kappa \sigma^{-1},
\end{aligned}
$$

and the first-order condition is given by

$$
\left(\Pi_{1}^{(-0)} r_{1}+C \Pi_{1}^{(-0)} \bar{r}+\kappa g\right) \Pi_{1}^{(-0)}+\beta \psi\left(\bar{r}+r_{1}\right)=0
$$

or, rearranged, as

$$
r^{*(-0)}=-\frac{\Pi_{1}^{(-0)} C \Pi_{1}^{(-0)} \bar{r}+\Pi_{1}^{(-0)} \kappa g+\beta \psi \bar{r}}{\left(\Pi_{1}^{(-0)}\right)^{2}+\beta \psi}
$$

This completes the full set of equilibrium conditions. Numerically, we solve for each possible case and throw out any solutions which violate the assumptions of that case. If multiple solutions exist, we choose the one that maximizes welfare. 